\title{
Single-particle Raman spectroscopy for studying physical and chemical processes of atmospheric particles
}

\author{
Zhancong Liang ${ }^{1}$, Yangxi $\mathrm{Chu}^{2}$, Masao Gen ${ }^{3}$, and Chak K. Chan ${ }^{1}$ \\ ${ }^{1}$ School of Energy and Environment, City University of Hong Kong, Hong Kong, 999077, China \\ ${ }^{2}$ State Key Laboratory of Environmental Criteria and Risk Assessment, Chinese Research Academy of \\ Environmental Sciences, Beijing, 100012, China \\ ${ }^{3}$ Faculty of Frontier Engineering, Institute of Science and Engineering, Kanazawa University, \\ Kanazawa, 920-1192, Japan \\ Correspondence: Chak K. Chan (chak.k.chan@cityu.edu.hk)
}

Received: 21 May 2021 - Discussion started: 26 May 2021

Revised: 13 December 2021 - Accepted: 17 January 2022 - Published: 7 March 2022

\begin{abstract}
Atmospheric particles experience various physical and chemical processes and change their properties during their lifetime. Most studies on atmospheric particles, both in laboratory and field measurements, rely on analyzing an ensemble of particles. Because of different mixing states of individual particles, only average properties can be obtained from studies using ensembles of particles. To better understand the fate and environmental impacts of atmospheric particles, investigations on their properties and processes at a single-particle level are valuable. Among a wealth of analytic techniques, single-particle Raman spectroscopy provides an unambiguous characterization of individual particles under atmospheric pressure in a non-destructive and in situ manner. This paper comprehensively reviews the application of such a technique in the studies of atmospheric particles, including particle hygroscopicity, phase transition and separation, and solute-water interactions, particle $\mathrm{pH}$, and multiphase reactions. Investigations on enhanced Raman spectroscopy and bioaerosols on a single-particle basis are also reviewed. For each application, we describe the principle and representative examples of studies. Finally, we present our views on future directions on both technique development and further applications of single-particle Raman spectroscopy in studying atmospheric particles.
\end{abstract}

\section{Background}

Atmospheric particles or aerosols have considerable effects on climate and human health (Seinfeld and Pandis, 2016). In general, atmospheric particles can originate from a wide variety of anthropogenic and natural sources. Primary particles are emitted directly as a liquid or solid (e.g., soot particles, mineral dust), and they can also undergo atmospheric multiphase reactions. Secondary particles can also be generated by gas-to-particle conversions, such as new particle formation via nucleation and condensation (Pöschl, 2005). During their atmospheric lifetime, both primary and secondary particles are subject to physical and chemical processes, such as partitioning and multiphase reactions. For liquid particles, gas- particle partitioning takes place to achieve thermodynamic equilibrium. For example, an increase or decrease in relative humidity $(\mathrm{RH})$ would result in the uptake of the water vapor into deliquescent particles or the evaporation of particulate water to the gas phase, respectively. Multiphase reactions can be described as gas-particle partitioning accompanied by chemical reactions. Furthermore, photochemistry is an important group of multiphase reactions during the daytime. Both partitioning and chemical reactions can change the composition of the particles, altering their properties such as hygroscopicity, cloud condensation nuclei (CCN) activities, phase state, morphology, reactivity, toxicity, and, finally, environmental impacts. 
Physical and chemical processes of atmospheric particles have been examined by numerous experimental approaches: a flowing stream of aerosol particles in an open system (flow tube) (Li et al., 2015; Duporté et al., 2017; Heine et al., 2018; Liu and Abbatt, 2020; T. Liu et al., 2020; Peng and Jimenez, 2020), a chamber of suspending particles (smog chamber) (Akimoto et al., 1979; Behnke et al., 1988; Liu et al., 2016; Ye et al., 2018; Charan et al., 2019; Liu and Abbatt, 2021; Qin et al., 2021), a collection of deposited particles (Bao et al., 2018; Y. Zhang et al., 2020), and single particles (Lee and Chan, 2007a; Krieger et al., 2012; Davies and Wilson, 2016; Gen et al., 2019c; Gong et al., 2019; Sullivan et al., 2020). An aerosol flow tube is one of the most common approaches employing a flowing stream of aerosol particles. It enables real-time characterization of reaction products and particulate size under controlled conditions (e.g., RH, temperature), with instruments connected to the exit or different outlets along the flow tube reactor. Oxidation flow reactors (OFRs) are analogous to the general aerosol flow tube, but photooxidants (e.g., OH radical) are introduced to examine secondary organic matter formation (Kang et al., 2007; Smith et al., 2009; George and Abbatt, 2010; Keller and Burtscher, 2012). Typically, higher concentrations of reactive precursor gases than ambient concentrations are used in these flow systems to compensate for the relatively short residential time (e.g., seconds) of the reactants. However, such equivalency of exposure may not necessarily hold (Lee and Chan, 2007b; Chu et al., 2019). Smog chambers enable simulations of various environmental conditions, including gas concentrations, for studying the formation and chemical transformation of particles. The residence time of particles can be extended to a few hours, but other limitations exist, such as long response time to control or change conditions, high cost, and wall loss of particles (Kang et al., 2007). Deposited particles can be studied using a sampleloaded substrate/filter placed in a flowing-gas reactor or a flow tube with its internal wall coated with particles. Environmental conditions can be easily varied, and the reaction time can be very long. An in situ analyzer for spectroscopic analysis can be equipped (e.g., Raman, Fourier transform infrared spectrometry (FTIR)) since the particles are immobilized on a substrate/filter. However, a large number of particles or large particles are usually required to achieve sensitive detection. The influence of particle loading on the reactions and chemical characterization is a challenging question. In general, these approaches produce statistical results of a collection of particles. They may not truly reflect the interaction between gas and particle since the composition of the individual particles may not be identical (Ault and Axson, 2017).

Single-particle characterization has the advantage that the physical and chemical processes undertaken by the particle can be unambiguously monitored. While there is a wealth of instruments for comprehensively characterizing single particles, some are destructive (e.g., mass spectroscopy) or operate under vacuum conditions (e.g., electron microscopy), making them unsuitable for monitoring the gas-particle interaction on the same particles. Single-particle spectroscopic methods (e.g., Raman) can be good alternatives, but the particles are usually supermicron and up to tens of microns. The findings from particles much larger than ambient ones need to be interpreted carefully for drawing implications in submicron atmospheric particles.

Despite its requirements of relatively large particles for spectroscopic signals, single-particle Raman spectroscopy offers several advantages for studying atmospheric processing of aerosol particles. First of all, a single particle can be unambiguously characterized in situ without destruction. From the Raman spectra, chemical compositions of typical aerosol particles (i.e., soot, sulfate, organics, etc.) can be identified by their characteristic peaks. Interactions between molecules can be inferred by peak shifts and changes in peak width. Particulate properties such as the phase state and size can also be characterized by coupling levitation (or isolation) technique and optical microscopy. We will elaborate on the applications of these functions later.

Furthermore, Raman analysis is operated under atmospheric pressure and enables the use of atmospherically relevant concentrations for a long exposure time to examine atmospheric gas-particle interactions (Lee and Chan, 2007a). Micro-Raman systems can provide spatial information of chemical species at 2-D or even 3-D levels (Batonneau et al., 2006; Sobanska et al., 2006, 2014, 2015; Tripathi et al., 2009; Scolaro et al., 2009; Offroy et al., 2015; Falgayrac et al., 2018; Ao et al., 2020). Recent advances in stimulated Raman scattering by micro-Raman spectroscopy further improve the spatial resolution from $1 \mu \mathrm{m}$ to $350 \mathrm{~nm}$ and significantly shorten the scanning time from $2.5 \mathrm{~h}$ to $2 \mathrm{~s}$ (Ao et al., 2020). The disadvantage of Raman spectroscopy is that it can only detect Raman-active functional groups but cannot provide information on the exact molecular structures. Lightabsorbing chemicals such as humic-like substances (HULIS) or some brown carbon species may generate fluorescence, interfering with the peak identification in the spectra (Ivleva et al., 2007a). Therefore, single-particle Raman spectroscopy is more suited for laboratory-generated particles than ambient particles. FTIR does not suffer from fluorescence since it uses a longer wavelength (up to tens of $\mu \mathrm{m}$ ), but the long wavelength also lowers the spectral resolution (Ault and Axson, 2017). Also, Raman scattering has advantages over FTIR for water-containing samples because the strong water peaks in the latter can mask the peaks from other components or even make them undetectable (Nishikida et al., 2018).

This paper will introduce the general setup of the singleparticle Raman spectrometer, how single particles can be characterized unambiguously, and examples of physical and chemical processes reported in the literature. We focus on applications of atmospheric relevance and refer readers to other literature on the principles of Raman spectroscopy and related techniques (e.g., stimulated Raman or coherent anti- 
Stokes Raman spectroscopy) and applications of less direct atmospheric relevance (Tolles et al., 1977; Efremov et al., 2008; Jones et al., 2019). Finally, we will provide suggestions on future directions of Raman spectroscopy for atmospheric particle studies.

\section{General setup of single-particle Raman spectroscopy}

\subsection{Particle isolation}

In general, single-particle Raman spectroscopy consists of two key components: particle isolation and Raman spectroscopy, including micro-Raman and confocal Raman configurations. One of the most popular approaches for singleparticle isolation is particle levitation, which has been discussed in a few reviews (Reid and Mitchem, 2006; Mitchem and Reid, 2008; Krieger et al., 2012). In this paper, we will briefly introduce their principles and configurations and focus on atmospheric applications. Techniques for levitation of particles can be mainly divided into electrical, optical, and acoustic trapping. Another approach for particle isolation is particle deposition onto substrates with Raman analyses of single particles on an individual basis.

\subsubsection{Electrodynamic balance}

The electrodynamic balance (EDB) has been used for studying single particles with a diameter of $1-100 \mu \mathrm{m}$ since the 1980s (Davis and Ray, 1980). A particle is levitated and trapped at the null point under the alternating current (AC) and direct current (DC) electric fields in the EDB. In the absence of other forces, the gravitational force of the particle trapped in the EDB is equal to the balancing electrostatic force, as shown in Eq. (1):

$m g=n q C \frac{V_{\mathrm{DC}}}{z}$

where $m$ is the mass of the particle, $g$ is the gravitational constant, $n$ is the number of elementary charges present on the particle, $q$ is the elementary charge, $z$ is the distance between two electrodes for the DC voltage, $C$ is a constant dependent on the geometrical configuration of the EDB, and $V_{\mathrm{DC}}$ is the balancing DC voltage required to levitate the particle stationary. According to Eq. (1), the mass of the particle is proportional to the DC voltage needed to balance its gravitational force, assuming that the charge present on the trapped particle remains constant. Hence, the relative mass change in the particle undergoing any physical or chemical processing can be quantified by measuring the balancing DC voltage. With a levitated particle stationary, Raman spectroscopy of the stably trapped particles can provide chemical information. Coupled with mass change measurements and optical microscopy, physical and chemical characterization of single particles can be in situ monitored. In addition to the traditional single-particle EDB (Davis and Ray, 1980; Chan et al., 1992), other EDB setups, for example, quadrupole (Q)EDB and comparative kinetic (CK)-EDB, have been developed. Q-EDB allows the trapping of multiple droplets simultaneously. During chemical reactions, individual particles are released one at a time for mass spectroscopy analysis, while the rest of the particles are kept levitated for in situ spectroscopic characterization (Singh et al., 2017, 2018; Jacobs et al., 2017; Kohli and Davies, 2021). CK-EDB employs a reference droplet with known composition and hygroscopic property, which serves as an accurate probe for the environmental conditions in which the tested droplet is examined. It affords hygroscopicity measurements and mass-transfer kinetic measurements on the droplets at high RH (>99\%) (Davies et al., 2013; Rovelli et al., 2016; Marsh et al., 2019).

\subsubsection{Optical trapping}

Optically traps can be basically categorized into radiation pressure trap, photophoretic trap, and universal optical trap. Radiation pressure trap, which is the most general in studying aerosol particles, utilizes the radiation pressure from a light source to balance the weight of the levitated particle (Ashkin, 1970). During optical trapping, the particle interacts with a highly focused laser beam and experiences scattering and gradient forces (Ashkin and Dziedzic, 1981; Mitchem and Reid, 2008). The scattering force is proportional to the square of the induced dipoles and the intensity of the incident laser beam, acting as a force along the direction of the beam propagation. In contrast, the gradient force derives from the focusing of the laser beam and draws the particle towards the region with the highest light intensity (Krieger et al., 2012).

Radiation pressure-based optical levitation and optical tweezers are two typical optical-trapping techniques utilizing these two forces. While optical levitation relies on the exact balance between downward gravitational force and upward scattering force, optical tweezers effectively create a strong intensity gradient in three dimensions by tightening the focus of the laser beam to generate amplified gradient forces. Optical tweezers provide a more robust trap with the gradient force typically many orders of magnitude larger than the scattering and gravitational forces, leading to three-dimensional confinement in position with a single laser beam. However, particle size changes must be accompanied by dynamic changes in the light intensity for retaining the trapped particle. In principle, transparent non-absorbing particles of 1$100 \mu \mathrm{m}$ in diameter can be trapped with dynamic light intensity adjustment for droplet size changes. By configuring a Bessel laser beam, instead of the typical Gaussian beam, in either vertically or horizontally trapping arrangements, optical levitation and tweezers can be applied for trapping submicron particles (Meresman et al., 2009; Cotterell et al., 2014; Lu et al., 2014). However, Raman spectroscopy would require larger particles for sufficient signal-to-noise ratios. A 
recent study reported a photochemical study of aerosol particles using an optical trap for the first time by employing a custom-built photochemical levitation chamber (Gómez Castaño et al., 2019). A sidewall of the chamber is equipped with quartz windows for a UV lamp.

In addition to radiation pressure traps, photophoretic traps and universal optical traps are two emerging alternatives (Redding et al., 2015a; Redding and Pan, 2015). The former is specifically for light-absorbing particles. The latter employs a hollow beam to trap transparent and light-absorbing particles using radiation pressure force and photophoretic force, respectively (Gong et al., 2018a). Using these techniques, Raman characterizations have been made on lightabsorbing particles in recent years, including bioaerosols (C. Wang et al., 2015; Redding et al., 2015a, b; Gong et al., 2018b, 2019), aromatic compounds (Kalume et al., 2017a, b; Gong et al., 2018b), carbon nanotubes (Pan et al., 2012; Gong et al., 2018b), and soot (Uraoka et al., 2017).

\subsubsection{Acoustic levitation}

Compared to the EDB and optical trap, acoustic levitation is less utilized in atmospheric research due to the complicated acoustic streaming and the requirement for large particles (20 $\mu \mathrm{m}-2 \mathrm{~mm}$ ) (Cohen et al., 2020; Jones et al., 2021). In an acoustic levitator, high-frequency sound waves generated by a piezo-electric radiator reflect from a concave-shaped reflector to generate a standing wave. The latter produces acoustic radiation pressure on the particle, levitating and trapping it against the gravitational force. It has been reported that a single particle can be firmly trapped by acoustic levitation under $15 \mathrm{~h}$ continuous irradiation (Tobon et al., 2017; Seng et al., 2018).

\subsubsection{Deposited particles}

In addition to single-particle levitation, deposited particles on a surface provide a convenient platform for single-particle Raman spectroscopy. While levitation can trap few particles for investigation, surface-based isolation affords a relatively large number of single particles, which can support further offline characterizations. However, the direct contact between particle and substrate may induce solute nucleation or phase separation that causes unexpected modification in particulate morphology. Hence, hydrophobic substrates are often used to study supersaturated aqueous droplets by reducing the particle and substrate contact area. Investigations on photochemistry can be easily performed by coupling a transparent substrate and an additional light source beneath the quartz window at a flow cell's bottom (Gen et al., 2019c, 2020). A single particle can be retained for an infinite time deposited, facilitating studies of slow processes in the atmosphere. However, Raman scattering from the substrate could also show interference.

\subsection{Raman spectroscopy}

A single-particle Raman spectroscopy setup generally involves a laser for excitation, followed by collection optics to detect the Raman signals analyzed by a spectrometer with a monochromator and a charge-coupled device (CCD) detector. The Raman peak location and intensity/area provide information on the speciation and abundance of specific particulate components. Appendix A summarizes the Raman peak assignment of representative atmospheric species. A Raman peak can also shift its location (in wavenumber) and change in the full width at half maxima (FWHM) as a response to variations of local bonding environments, such as molecular interaction and phase transition. Furthermore, Raman emissions from spherical particles (e.g., levitated droplets) can be complicated by resonance modes at discrete wavelengths triggered by cavity-enhanced Raman scattering (CERS) (Miles et al., 2012) or so-called size parameters in the spectra. These resonant modes are often called morphology-dependent resonance (MDR) or whispering gallery modes (WGMs) (Chan et al., 1991; Krieger et al., 2012). They can be used to accurately determine size with a resolution down to $\sim 5 \mathrm{~nm}$, refractive index, and even shell-core morphology of the mixed organic-inorganic particles based on the Mie theory (Gorkowski et al., 2017, 2020; Rafferty and Preston, 2018; Sullivan et al., 2020). The optical effects complicate the Raman measurements for chemical analysis, although they provide additional information for the sizing and refractive index of the particles based on Mie theory. We refer readers to the references for the interactions between Mie scattering and Raman spectroscopy (Chan et al., 1991; Krieger et al., 2012; Nadler et al., 2019). Micro-Raman is a combined system that uses an optical microscope for guiding the laser to analyte particles and collect Raman scattering from the same microscope connected to a spectrometer. The Raman scattering signal-to-noise ratio can be enhanced since the incident laser energy is focused on a small volume through a high magnification (and short working distance) objective. Furthermore, 2-D Raman imaging is possible in studying particles in the order of tens of microns (Eom et al., 2016; Zhao et al., 2018). Confocal Raman microspectroscopy eliminates the Raman scattering from volumes other than the focal volume by configuring additional slits in the spectrometer. Confocal Raman provides depth profiles of constituent information of the particle (Scolaro et al., 2009).

This paper focuses on the use of single-particle Raman spectroscopy to examine the physical and chemical processes of atmospheric particles. We describe techniques of particle maneuvering that allow single-particle Raman spectroscopy such as EDB, deposited particles, and optical trapping. However, it is not our intention to conduct a detailed examination of the application of these techniques beyond single-particle Raman spectroscopy. Hence, in this review, we put less emphasis on literature related to other applications of these trapping techniques. We focus on investigating these physical 
and chemical processes of particles by Raman instead of the particle properties or detailed descriptions of these processes investigated by other techniques. The overall aim of the paper is to introduce single-particle Raman spectroscopy as a useful tool to examine a host of processes of atmospheric relevance.

\section{Characterization of single particles}

\subsection{Hygroscopicity and phase transition}

Depending on the environmental RH, type of solutes, and size of the particles (Kelvin effect), atmospheric particles can absorb/release an appropriate amount of water to reach equilibrium with the gas phase; i.e., the partial water vapor pressure above the particle surface equals to that of the gas phase. Hygroscopic properties include water uptake/evaporation and phase transition as a response to changes in ambient $\mathrm{RH}$. Upon water uptake/evaporation, the particle size change alters the particulate capacity in scattering light, and particles can also be activated to cloud condensation nuclei (Tang et al., 2019). In this paper, we focus on subsaturated ( $\mathrm{RH}<100 \%)$ environments. The phase states determine the water uptake behaviors of the atmospheric particles (Pajunoja et al., 2016; Rosati et al., 2020). They can be generally divided into liquid (i.e., aqueous), crystalline, and amorphous (e.g., ultra-viscous, gel, rubber, glasses). Both crystalline and amorphous particles are solids, but only the latter can absorb water reversibly, while the former shows hysteresis in water uptake. At increasing $\mathrm{RH}$, water uptake increases the aerosol liquid water (ALW) content of deliquescent/amorphous particles and their size and ability to scatter light. A recent study showed that the poor visibility during haze in the North China Plain is positively correlated to the ALW (Z. Wu et al., 2018). When crystalline particles are exposed to increasing $\mathrm{RH}$, they will initially adsorb a small amount of water on its surface, the so-called surfaceadsorbed water (SAW), and then uptake a significant amount of water vapor abruptly to become aqueous droplets at the deliquescence RH (DRH). The DRH is the RH at which a droplet attains the saturated salt concentration, ignoring the influence of the Kelvin effect, which is often the case for single-particle Raman analysis (particle size $>10 \mu \mathrm{m}$ ). At decreasing RH, a droplet loses water to become supersaturated and finally may effloresce to form crystalline particles at the efflorescence RH (ERH). Typical inorganic atmospheric components of $\left(\mathrm{NH}_{4}\right)_{2} \mathrm{SO}_{4}, \mathrm{NH}_{4} \mathrm{NO}_{3}$, and $\mathrm{NaCl}$ deliquesce at $\sim 80 \%, \sim 62 \%$, and $\sim 75 \%$ RH but effloresce at $34 \%-$ $48 \%, 0 \%-30 \%$, and $39 \%-54 \%$, respectively. Many studies show that nitrates and some organics do not effloresce even at low RH (e.g., below $5 \%$ ) (Mikhailov et al., 2009; Yeung and Chan, 2010). In general, organics with high solubility (e.g., malonic acid) tend to remain a supersaturated liquid state or amorphous state at low RH (Krieger et al., 2012). Unlike DRH, which is thermodynamically well defined, ERH is a stochastic property that relates to the kinetics of nucleation and presence of impurities. It has been reported that sucrose crystals deliquesce at $85.6 \%$ RH upon humidification, but the aqueous droplets turn into a glassy amorphous state upon drying instead of forming crystallized solids (Zobrist et al., 2011). Using EDB and optical trap experiments, hygroscopic changes and phase transition RH values that involve rapid changes in mass or size can be measured by the balancing voltage and light scattering, respectively. The growth factor (GF) in terms of mass or size ratios as a function of water activity or RH, DRH, and ERH can be easily determined by changes in mass or size and the light-scattering pattern (Chan et al., 2005; Mitchem et al., 2006; Marsh et al., 2017).

While GF, DRH, and ERH measurements are readily made for mixed particles using EDB and optical traps, the formation of mixed-phase particles before full deliquescence is more complicated. For example, unlike the corresponding single inorganic salts, $\mathrm{NaCl}$-malonic acid and $\left(\mathrm{NH}_{4}\right)_{2} \mathrm{SO}_{4}$ malonic acid mixed particles absorb a significant amount of water before their DRH since malonic acid absorbs water reversibly without crystallization (Lee et al., 2008a). However, these stepwise water uptake and phase transition behaviors could not be explained by EDB/optical levitation mass or size measurements alone, due to the lack of chemical characterization. Raman spectroscopy offers complementary information on the water uptake behaviors and phase states of Raman-active species (Yeung and Chan, 2010; Li et al., 2017). For example, the water-to-solute ratio (WSR) as a function of ambient RH can be easily determined from the integrated peak area ratio of the water $v(\mathrm{O}-\mathrm{H})$ to that of the solute (e.g., sulfate, nitrate) after proper calibration. Also, the full width at half maxima (FWHM) of the characteristic peaks is sensitive to the phase state of the solute. In general, a species in the liquid phase has a larger FWHM than in the solid phase because the less compact molecular arrangement allows minor variations in vibration. In Fig. 1a and $\mathrm{b}$, as the RH decreased to $39.5 \%$ for ammonium sulfate (AS) and $19 \%$ for ammonium nitrate (AN), crystallization can be inferred by the red shift and decrease in FWHM of sulfate and nitrate peaks, as well as the disappearance of water peak. On this basis, the mixed-phase particle prior to full deliquescence can be characterized by FWHM of different Raman-active components. For instance, Ling and Chan found an increased FWHM of nitrate peak $\left(\sim 730 \mathrm{~cm}^{-1}\right)$ at $\sim 67 \% \mathrm{RH}$, followed by an increased FWHM of sulfate peak $\left(\sim 450 \mathrm{~cm}^{-1}\right)$ at $\sim 76 \mathrm{RH} \%$ for mixed-phase AS-AN particles when RH increased (Fig. 1c, d). These changes indicate that AN deliquesced before AS did upon humidification, and the mixed-phase AS-AN particle was composed mainly of aqueous AN and crystalline AS. The accuracy of single-particle Raman spectroscopy in determining hygroscopicity has been verified by thermodynamic models such as E-AIM and UNIFAC (Peng et al., 2001; Yeung and Chan, 2010). There are numerous hygroscopicity applications on various specific systems, including model inorganics, organ- 
ics, and their mixtures (Chu et al., 2015; Laskina et al., 2015; W. Wang et al., 2021; Tobon et al., 2021; C. Zhang et al., 2021; Ashraf et al., 2021), as well as mineral dust (Liu et al., 2008), secondary organic aerosols (Wu et al., 2020), and atmospherically relevant biological macromolecules (Mael et al., 2021), using single-particle Raman spectroscopy. It should be noted that evaporation of some components and precipitation of some salts could occur during the RH cycling in hygroscopicity measurements ( $\mathrm{Li}$ et al., 2017, 2021; Cai and Zhao, 2018; Ma et al., 2019a, b; Wu et al., 2020). Singleparticle Raman spectroscopy can probe such processes in situ by the disappearance of some characteristic peaks (evaporation) or changes in their FWHM (precipitation) (Braban et al., 2003; Wang et al., 2017).

\subsection{Solid-phase transition}

In addition to liquid-solid-phase changes, transitions can occur between solid phases, from a metastable one to a stable one at a specific temperature. Many organics are known to form polymorphs, defined as solids with the same chemical composition but distinctive properties such as thermal stability and solubility due to different structures (Krieger et al., 2012). Different polymorphs of the same compound can exhibit different Raman characteristics, which can identify different solid states and their transition. For example, crystalline glutaric acid (GA) particles could exist as the metastable $\alpha$-form and the thermodynamically stable $\beta$ form at room temperature, and $\alpha$-form GA tends to transfer into $\beta$-form. Using EDB-Raman spectroscopy, Chan et al. (2006) coated GA on AS particles by coagulation of small GA particles formed by nucleation. Raman spectra showed the existence of $\alpha$-form GA in the freshly coated particles, but then the $\beta$-form was detected after a deliquescence-crystallization cycle (Chan et al., 2006). Ling and Chan (2008) reported the formation of the $\alpha$-form GA solid in a freshly crystallized GA-AS particle. The $\alpha$-form GA solid gradually transformed to the $\beta$-form at $60 \% \mathrm{RH}$ in $3 \mathrm{~h}$ at room temperature (Ling and Chan, 2008). Furthermore, Yeung et al. (2010) examined the effects of polymorphism on the hygroscopic properties of GA particles using micro-Raman (Yeung et al., 2010). By evaporation at room temperature, $\alpha$-form and $\beta$-form solid particles were formed $(\alpha: \beta \approx 5: 1)$. It was observed that the $\alpha$-form deliquesced at $85 \%-86 \% \mathrm{RH}$, whereas the $\beta$-form deliquesced at $90 \% \mathrm{RH}$. Furthermore, the $\alpha$-form is transformed to the $\beta$-form at $86 \% \mathrm{RH}$ instead of achieving full deliquescence (Fig. 2). This solid-phase transition behavior was used to explain the discrepancies of DRH values of glutaric acid particles reported based on different literature measurements (Cruz and Pandis, 2000; Peng et al., 2001; Choi and Chan, 2002; Parsons et al., 2004; Zardini et al., 2008; Treuel et al., 2009). Polymorphism also exists in atmospherically relevant inorganics. For example, AN can exist in five stable polymorphic forms with distinct Raman spectra, depending on the temperature. In atmospheric research, very little attention has been paid to the solid-phase transitions of AN because phase IV AN particle is stable over a wide range of tropospheric temperatures (from -17 to $32^{\circ} \mathrm{C}$ ) (Wu et al., 2007). Nevertheless, Wu and Chan (2008) reported that the $\mathrm{KNO}_{3} / \mathrm{AN}$ mixed particles undergo the IV-III transition under ambient temperatures at a relatively high mass percentage of $\mathrm{KNO}_{3}(\geq 7.4 \mathrm{wt} \%)$ or even crystallize directly in phase III from droplets with a further increase in the mass percentage of $\mathrm{KNO}_{3}$ (Wu and Chan, 2008).

Another typical solid-phase transition is between stable and metastable double salts. Like metastable/stable polymorphs, metastable double salts show Raman characteristics different from stable ones, likely due to specific molecular interactions. Ling and Chan (2007) observed the doublesalt $3 \mathrm{AN} \cdot \mathrm{AS}$, not predicted from thermodynamics, in the freshly crystallized mixed single particles of AN and AS using single-particle Raman spectroscopy (Ling and Chan, 2007). The existence of double salts indicates that $\mathrm{AN}$ and AS likely crystallized simultaneously. The degree of metastability could depend upon the crystallization processes of the particles. Besides, it takes several hours to more than a day, depending on $\mathrm{RH}$, for a freshly crystallized metastable ASAN double-salt particle to reach its stable form, suggesting a high possibility that metastable solids persist in the atmosphere when the ambient RH is sufficiently low. The AN-AS double salts were recently reported in ambient particles in Beijing (Sun et al., 2019b; M. Wang et al., 2021).

\subsection{Molecular interactions between particulate water and solutes}

In general, characterizations on phase transitions rely on the sensitivity of Raman spectroscopy in probing the bonding environment of components in the particles. Raman spectroscopy can also characterize the interactions between the solutes and particulate water, such as hydrogen/ionic bonding. For example, the Raman shift of strongly hydrogenbonded water $\left(\sim 3500 \mathrm{~cm}^{-1}\right)$ is generally higher than that of water monomers $\left(\sim 3300 \mathrm{~cm}^{-1}\right)$ (Zhang and Chan, 2003). At low RH, the elevated concentration of electrolytes leads to more significant disruption of the hydrogen bonding environment of the water molecules, resulting in a shift of $\mathrm{OH}$ stretching peak at $3480 \mathrm{~cm}^{-1}$ to higher frequencies. In contrast, the low-frequency shoulder at $3290 \mathrm{~cm}^{-1}$ diminishes. Thus, the shape of water peaks in Raman spectra can reflect the ionic strength of the particle, which is an essential parameter for aerosol chemistry (Mitchem et al., 2006; Mekic et al., 2020). The sensitive shift of water peak has also been used in studying ice nucleation properties such as depositional freezing (Wise et al., 2010, 2012) and immersing freezing (Knopf et al., 2002, 2003). Specifically, while liquid water peaks are usually located at $\sim 3400 \mathrm{~cm}^{-1}$ with a shoulder at a lower wavenumber, a sharp peak at $\sim 3150 \mathrm{~cm}^{-1}$ with shoulder peaks at $\sim 3200 \mathrm{~cm}^{-1}$ appears as water is frozen 

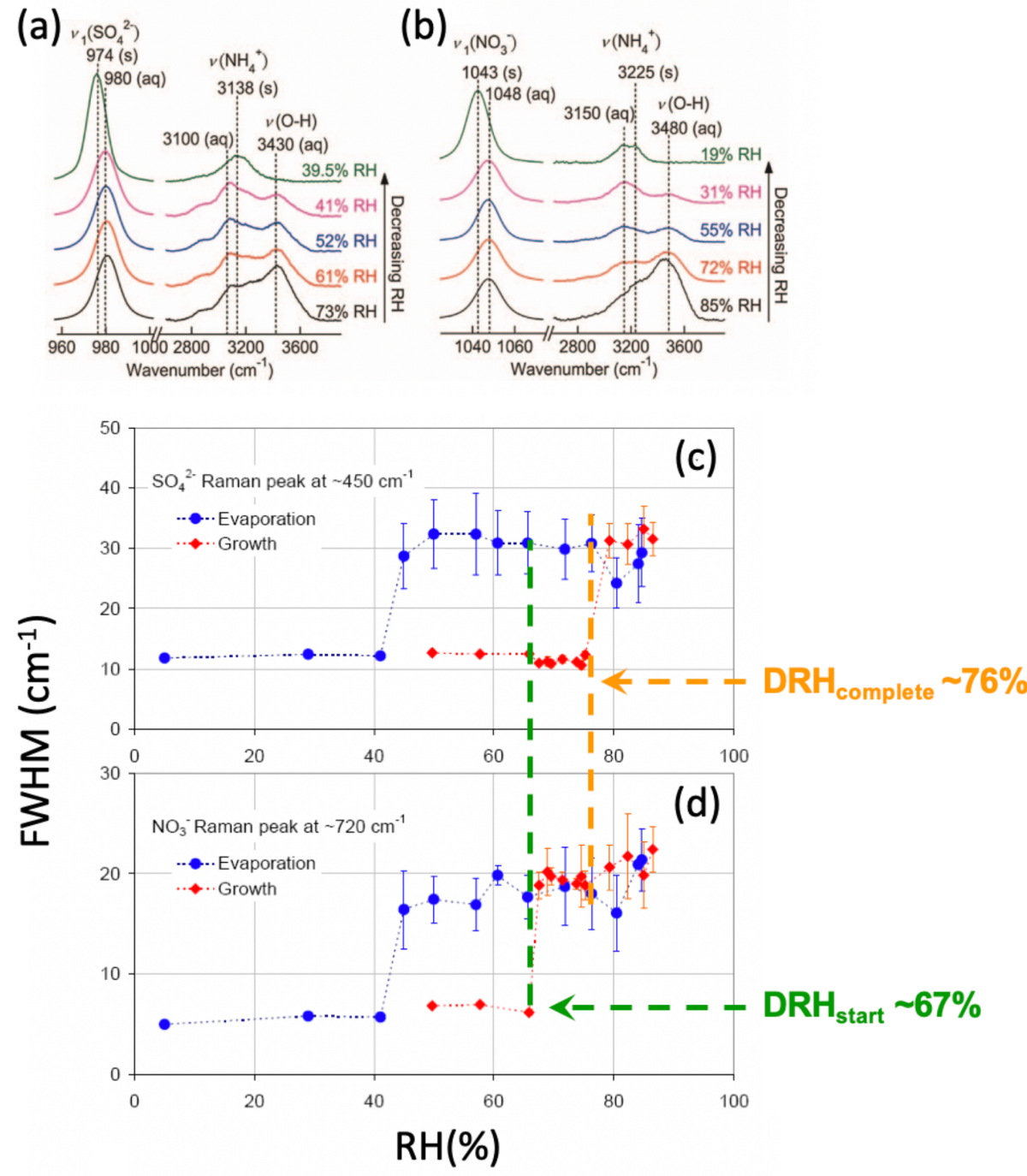

Figure 1. Raman spectra of a single (a) AS and (b) AN particle upon evaporation (Yeung and Chan, 2010). FWHM of (c) $\mathrm{SO}_{4}^{2-}$ peak and (d) $\mathrm{NO}_{3}^{-}$peak during the evaporation-growth cycle of a mixed AS-AN particle.

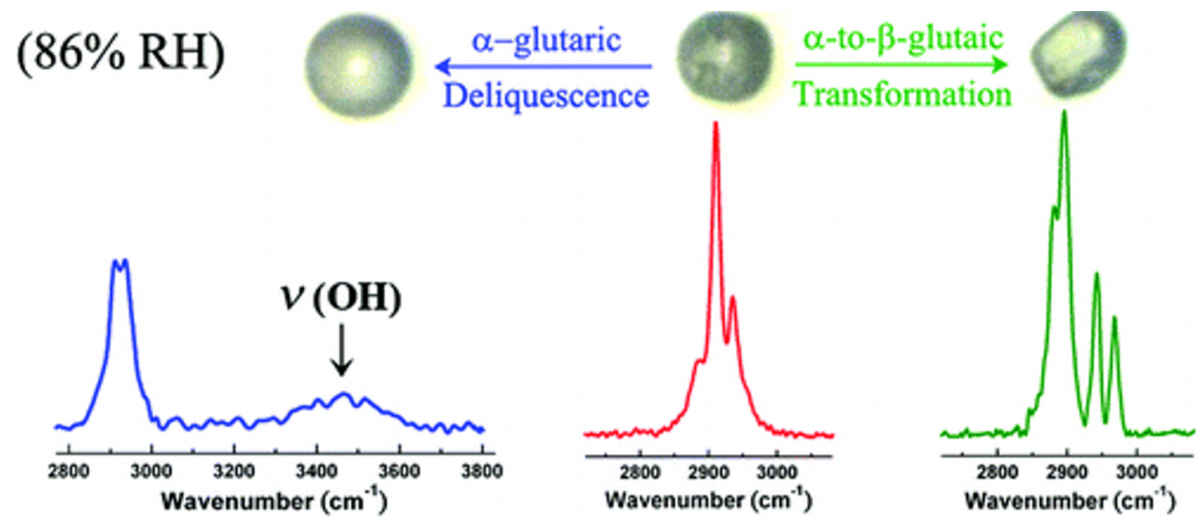

Figure 2. Raman spectra of deliquescent $\alpha$-glutaric acid, crystalline $\alpha$-glutaric acid, and $\beta$-glutaric acid (Ling and Chan, 2007). 
(Schill et al., 2014; Mael et al., 2019). Besides, ionic bonding of inorganic salts (e.g., $\mathrm{SO}_{4}^{2-}, \mathrm{NO}_{3}^{-}$) can also be reflected by their Raman characteristics; and many of them have been further supported by theoretical calculations (Yu et al., 2012; Y. Wang et al., 2015; Zhu et al., 2018). For example, Zhang and Chan (2000) observed a blue shift of sulfate and nitrate Raman peaks and an increase in FWHM when the molar water to the solute ratio (WSR) in $\mathrm{MgSO}_{4}$ and $\mathrm{Mg}\left(\mathrm{NO}_{3}\right)_{2}$ particles decreases to less than six, the number of hydration of $\mathrm{Mg}^{2+}$ ions (Zhang and Chan, 2000; Zhang et al., 2004). These observations were attributed to direct contacting ion pairs formed between $\mathrm{Mg}^{2+}$ and anions, without water molecules between the ions. Besides, single-particle Raman spectroscopic analysis can reveal the structural heterogeneity of droplets. Raman imaging suggested that the $\mathrm{NO}_{3}^{-}$to $\mathrm{Mg}^{2+}$ ratio of the contact ion pairs increases but the $\mathrm{H}_{2} \mathrm{O}$ to $\mathrm{Mg}^{2+}$ ratio decreases as the surface of a highly supersaturated droplet is approached (Zhang et al., 2004). Yeung and Chan (2010) reported that though no crystallization was shown by glyoxylic acid particle even at $0 \% \mathrm{RH}$, a new $\mathrm{C}=\mathrm{O}$ peak at $\sim 1820 \mathrm{~cm}^{-1}$ appeared together with the aqueous $\mathrm{C}=\mathrm{O}$ peak at $1735 \mathrm{~cm}^{-1}$, possibly indicating the presence of anhydrate (Yeung and Chan, 2010).

\subsection{Liquid-liquid phase separation}

As mentioned above, partial crystallization can lead to a separation of solid and liquid mixed phases. Separation of two or even more liquid phases, namely liquid-liquid phase separation (LLPS), is also possible (Song et al., 2012a, 2018; Y. Huang et al., 2021; Ma et al., 2021). LLPS can be triggered by the interactions between inorganic and organic solutes and particulate water in mixed particles (You et al., 2012; Renbaum-Wolff et al., 2016). This phenomenon is mainly attributed to the low solubility of some non-polar or weakly polar organics, especially in the presence of inorganic salts, which may further decrease the solubilities of organics as the salting-out effects (Setschenow, 1889).

Optical microscopy (as a part of a single-particle Raman microscope) can directly indicate LLPS by the contrasting colors on appearance, based on the different refractive indices of materials in different phases (You et al., 2012). Single-particle (micro-)Raman spectroscopy can examine LLPS via spatial scanning (micro-Raman), optical imaging (micro-Raman), Raman imaging, and whisper gallery modes (WGMs) with additional chemical information of the different phases (Bertram et al., 2011; Song et al., 2012b). Spatial scanning records distinct micro-Raman spectra at different locations of the particle and reveals LLPS (Bertram et al., 2011; F. M. Wu et al., 2018) such as core-shell structures (e.g., an aqueous core surrounded by a BC-containing organic shell) (Brunamonti et al., 2015). However, Raman spatial scanning requires accurate focusing of the laser onto different targeted phases, which can be difficult when phases are separated into multiple small inclusions (Buajarern et al., 2007b).

Using spatial scanning and optical imaging, Ma et al. (2021) reported an organic-shell-aqueous-core LLPS in deposited 1,2,6-hexanetriol / ammonium sulfate mixed particles. However, different substrates for deposited particles could affect their LLPS behavior (Ma et al., 2021). Though LLPS of an organic / AS mixed particle has been observed on both hydrophobic (i.e., PTFE) and hydrophilic (i.e., glass) substrates, the former shows an organic shell with an AS inner core while the latter shows an opposite configuration (Q. Zhou et al., 2014). To eliminate interaction with substrates, Ishizaka et al. (2021) used levitated droplets and found both core-shell and partially engulfed LLPS. The observed configurations of two phases are well consistent with thermodynamic predictions based on interfacial tensions and relative volume ratios of two immiscible phases (Ishizaka et al., 2021).

Another approach for identifying LLPS is Raman imaging of the whole particle in one single measurement. Typical Raman measurements bin the vertical pixels of a CCD to enhance the signa-to-noise ratio, while the horizontal pixels represent the wave number after chromatic dispersion by a grating. Zhang et al. (2004) used collection optics to obtain an image of a particle in an EDB on the slit of a monochromator. Instead of using vertical binning, the vertical pixels registered the vertical profile of the Raman scattering (e.g., edge to center to edge) of the particle (Zhang et al., 2004). Chu and Chan (2017b) reported that the coreshell phase separation in a mixed sucrose-ammonium-sulfate particle with a sucrose molar fraction of $50 \%$ at $<5 \% \mathrm{RH}$ but not at $70 \%$ RH. As shown in Fig. 3a and b $(<5 \%$ RH), the accumulated $\mathrm{C}-\mathrm{H}$ signal on the two sides indicates the presence of an organic-rich coating and an organic-deficient core. In contrast, the even distribution of the $\mathrm{C}-\mathrm{H}$ signal in Fig. 3c (70\% RH) suggests that the particle is likely homogeneous (Chu and Chan, 2017b). Kalume et al. (2018) observed temporally resolved LLPS in a diethyl phthalate and glycerol mixed droplet. Upon evaporation, diethyl phthalate migrated to the surface and formed an outer layer, and glycerol was more concentrated in the interior of the droplet (Kalume et al., 2018).

Additionally, WGMs have also been utilized to infer the occurrence of LLPS and the specific particle morphologies. For example, different resonance structures appear in the Raman spectra when core-shell or engulfed phase separation occur (Buajarern et al., 2007a, b; Kwamena et al., 2010; Song et al., 2013; Marcolli and Krieger, 2020). Sharps peaks generated by WGMs in spectra can be found if the spatial distribution of particulate species is symmetric, such as those in core-shell separated and homogeneously mixed particles, though the number, location, and intensity of WGMs peaks are different. In contrast, the engulfed phase-separated particles do not show any WGMs peaks (Sullivan et al., 2020). Utilizing WGMs, Steward et al. (2015) reported the transi- 

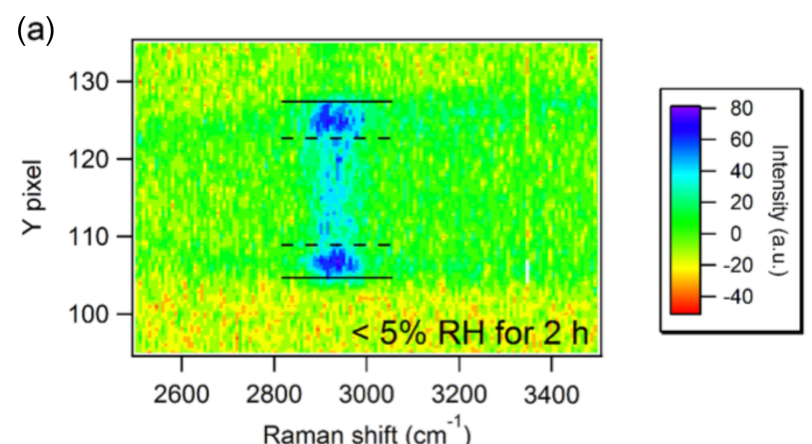

(b)
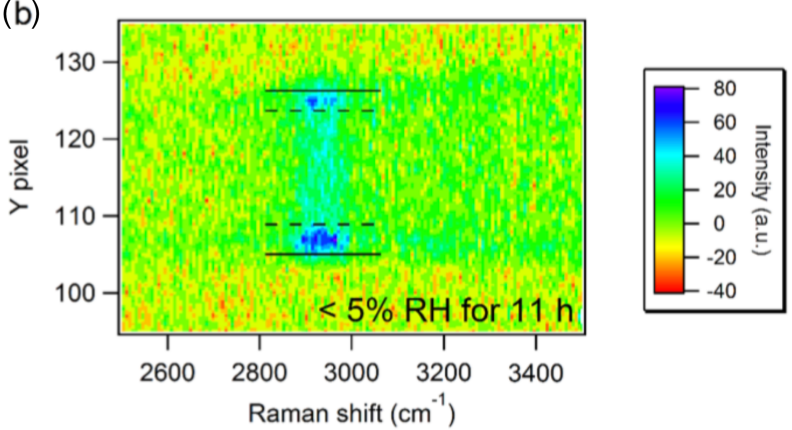

(c)
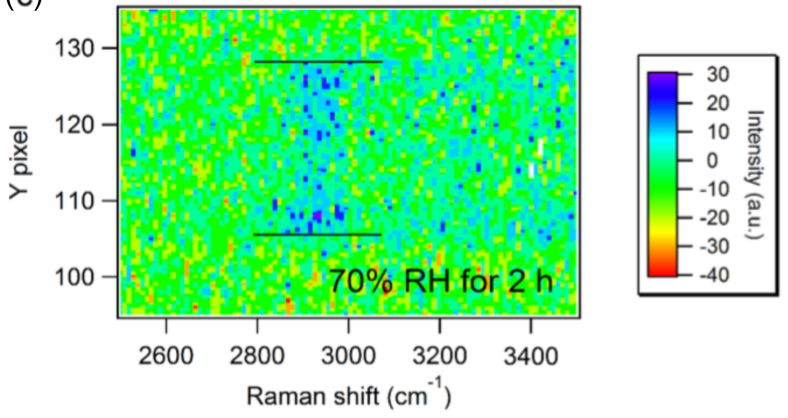

Figure 3. Spatially resolved Raman intensities of AS-sucrose (molar fraction of sucrose in total solute $\left.\left(F_{\mathrm{SU}}=0.5\right)\right)$ particles equilibrated at $<5 \% \mathrm{RH}$ for $2 \mathrm{~h} \mathrm{(a)} \mathrm{and} \mathrm{for} 11 \mathrm{~h}$ (b) and at $70 \% \mathrm{RH}$ for $2 \mathrm{~h}$ (c). C-H peaks at $\sim 2900 \mathrm{~cm}^{-1}$ represent sucrose. Solid lines indicate the particle's upper and lower edges. The outer regions between the dashed and solid lines are sucrose-rich in panels (a)-(b) (Chu and Chan, 2017b).

tion between partially engulfed and core-shell structure at different RH values (Stewart et al., 2015). However, these analyses focus on WGMs but not Raman as a chemical probing technique.

\subsection{Determination of $\mathrm{pH}$}

The $\mathrm{pH}$, defined as the activity of proton in aerosol particles, can also be inferred from Raman spectra based on the intensity of the conjugate acid-base ion pairs. Sulfate/bisulfate has been used most frequently. The $\mathrm{pH}$ can be determined by substituting the conjugate ion pair concentrations and its dissociation coefficient into Henderson-Hasselbalch $(\mathrm{H}-\mathrm{H})$ (Radić and Prkić, 2012), Debye-Hückel theory, and spe- cific ion interaction theory equations, respectively (Ciavatta, 1980; Rindelaub et al., 2016; Craig et al., 2017, 2018; Coddens et al., 2019; Chang et al., 2020a). The latter two are more suitable to supersaturated particles since non-ideality has been considered. Rindelaub et al. (2016) reported direct measurements of $\mathrm{pH}$ in individual deposited particles according to sulfate/bisulfate peaks in Raman spectra and its variation with RH (Rindelaub et al., 2016). Craig et al. (2017) extended this approach to a range of atmospherically relevant inorganic and organic acid-base equilibria systems covering a wide range of $\mathrm{pH}$ (from -1 to 10) (Craig et al., 2017). To eliminate the artifact of contacts between the particle and the substrate, Coddens et al. (2019) determined the $\mathrm{pH}$ of trapped particles via titration by coalescence of droplets containing strong acids (Coddens et al., 2019). Boyer et al. (2020) further utilized the WGMs for determining the solute concentration in real time and achieved uncertainties in $\mathrm{pH}$ measurements of picoliter droplets ranging from \pm 0.03 to $0.06 \mathrm{pH}$ units (Boyer et al., 2020). Very recently, Cui et al. (2021) reported that water can be used to probe $\mathrm{pH}$ in individual model aerosol particles (e.g., $\left.\left(\mathrm{NH}_{4}\right)_{2} \mathrm{SO}_{4}, \mathrm{NaCl}\right)$, since the water bands are affected by other components (e.g., ions), as discussed in Sect. 3.3. Specifically, the broad water peak at $2600-3800 \mathrm{~cm}^{-1}$ could comprise many overlapping peaks, representing $\mathrm{O}-\mathrm{H}$ vibration of water molecules in different local environments. The addition of solutes affects the local environment of water molecules and changes the relative intensities of the overlapped peaks. Hence, the activity of specific solutes can be obtained by analyzing the overlapped water peaks after rigorous calibration, and the $\mathrm{pH}$ of the aerosol particle can be calculated (Cui et al., 2021).

\section{Multiphase reactions}

In Sect. 3, applications of characterizing single particles have been reviewed. This section mainly focuses on the processes occurring on single particles. Taking water-solute interactions as an example, hygroscopicity describes the ability of solutes to absorb water upon equilibrium at fixed RH. Water uptake is a dynamic process, although it is generally too quick to be a limiting step in most atmospheric applications. However, in some viscous matrixes, the water uptake rate could be reduced by orders of magnitude due to the limited diffusion (Chang et al., 2020b). Taking advantage of the different Raman characteristics of $\mathrm{D}_{2} \mathrm{O}$ and $\mathrm{H}_{2} \mathrm{O}$, Davies and Wilson (2016) measured the diffusion coefficients of water molecules in trapped viscous particles by monitoring the isotopic exchange rate using Raman spectroscopy (Davies and Wilson, 2016). Determination of kinetic parameters of nonreactive processes such as partitioning coefficient, diffusion coefficient, and mass accommodation coefficient has been reviewed in another paper (Krieger et al., 2012). Hence, applications on probing multiphase reactions using single-particle Raman spectroscopy will be the focus below. 


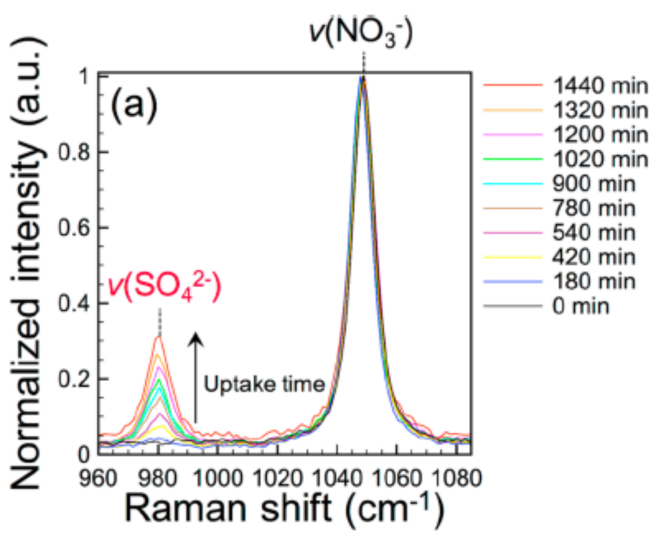

Figure 4. Sulfate formation during the photolysis of AN particles in the presence of $\mathrm{SO}_{2}$ at $80 \% \mathrm{RH}$ (Gen et al., 2019c).

\subsection{Multiphase formation of secondary inorganic aerosols (SIAs)}

Particulate sulfate and nitrate are two major secondary inorganic aerosols (SIAs). They have dominant Raman peaks at $\sim 980$ and $\sim 1046 \mathrm{~cm}^{-1}$, respectively. Probing multiphase formation of sulfate by single-particle Raman spectroscopy was first employed by Davis and co-workers for absorption of $\mathrm{SO}_{2}$ by alkali-metal hydroxides particles (Aardahl and Davis, 1996). In atmospheric applications, particulate sulfate formation has been a debating topic since the currently proposed pathways, including $\mathrm{O}_{3}, \mathrm{OH} \cdot, \mathrm{NO}_{2}, \mathrm{H}_{2} \mathrm{O}_{2}$, and transition metal ions (TMI) in cloud water, cannot entirely account for the high concentration of sulfate observed in haze events such as those in the North China Plain (NCP) (Cheng et al., 2016). Using single-particle micro-Raman spectroscopy, Chan and his group reported that oxidants, including $\mathrm{NO}_{2}$, $\mathrm{N}(\mathrm{III}), \mathrm{OH}$ radicals, etc., generated from particulate nitrate photolysis could effectively oxidize $\mathrm{SO}_{2}$ to sulfate (Gen et al., 2019c, b; R. Zhang et al., 2020; H. Zheng et al., 2020). Clear increase in the sulfate peak signal was identified in Raman spectra of UV irradiated nitrate particle (Fig. 4). Later, they also reported sulfate formation by multiphase oxidation of $\mathrm{SO}_{2}$ during $\mathrm{FeCl}_{3}$ photolysis (Gen et al., 2020). Recently, sulfate formation was used to indicate the synergistic effect of the coexistence of iron-organic complexes and nitrate under irradiation as a source of $\mathrm{N}(\mathrm{III})$, based on the reaction between $\mathrm{SO}_{2}$ and $\mathrm{N}(\mathrm{III})$ (Gen et al., 2021). Angle et al. (2021) reported an enhanced sulfate formation in TMIcontaining droplets compared to that in TMI bulk solutions. This enhancement is greater than what can be explained by the higher TMI/bisulfite concentrations in aerosol than in bulk. It suggests that surface effects and potentially aerosol $\mathrm{pH}$ gradients play important roles in the S(IV) oxidation process in aqueous aerosols (Angle et al., 2021).

The formation of nitrate has also been investigated. Zangmeister and Pemberton (2001) performed kinetic analysis on the reactions between deposited $\mathrm{NaCl}$ particles and gaseous
$\mathrm{HNO}_{3}$ based on the increase in the nitrate peak (Zangmeister and Pemberton, 2001). Tang et al. (2014) coupled optical levitation with Raman spectroscopy to investigate $\mathrm{N}_{2} \mathrm{O}_{5}$ uptake on $\mathrm{SiO}_{2}$ particle as a function of $\mathrm{RH}$ and found that particulate nitrate formation increased as RH increased. They conclude that the water content affects the partitioning of $\mathrm{HNO}_{3}$ between the gas phase and condensed phases (i.e., adsorbed phase and aqueous phase). More surfaceadsorbed water layers block the reactive sites for $\mathrm{N}_{2} \mathrm{O}_{5}$ uptake but promote $\mathrm{HNO}_{3}$ dissolution (Tang et al., 2014). Scolaro et al. (2009) studied the three-dimensional evolution of the $\mathrm{NaCl}(100)$ surface during its reaction with $\mathrm{NO}_{2}$ as a function of RH, using confocal Raman imaging combined with non-contact atomic force microscopy (AFM) (Scolaro et al., 2009). At $0 \% \mathrm{RH}$, a $\mathrm{NaNO}_{3}$ monolayer capping the $\mathrm{NaCl}(100)$ surface formed. $\mathrm{NaNO}_{3}$ tetrahedral crystals $(<0.5 \mu \mathrm{m})$ formed at $45 \% \mathrm{RH}$, and supermicron $\mathrm{NaNO}_{3}$ rhombohedral plates were obtained under the $\mathrm{H}_{2} \mathrm{O}$ multilayer regime $(45 \%<\mathrm{RH}<75 \%)$. At $\mathrm{RH}>80 \%$, both crystalline and aqueous $\mathrm{NO}_{3}^{-}$were found. Reactions were accelerated in the presence of water vapor due to the formation of reactive $\mathrm{HNO}_{3}$ by $\mathrm{NO}_{2}$ hydrolysis. Ault et al. (2014) reported that individual nascent sea spray aerosol particles showed different reactivity towards $\mathrm{HNO}_{3}$ and $\mathrm{N}_{2} \mathrm{O}_{5}$, likely due to compositional heterogeneity. After the same exposure of gaseous reactants, some particles showed intense $v\left(\mathrm{NO}_{3}^{-}\right)$ peak, whereas $v(\mathrm{C}-\mathrm{H})$ is still the dominant mode in some other particles (Ault et al., 2014).

There are also investigations on the simultaneous formation of particulate sulfate and nitrate. Zhao et al. (2018) reported a multi-step reaction mechanism of oxidation of $\mathrm{SO}_{2}$ by $\mathrm{NO}_{2}$ on deposited $\mathrm{CaCO}_{3}$ particles (Zhao et al., 2018). Further, Yu et al. (2018) reported that the uptake coefficient of $\mathrm{SO}_{2}$ on $\mathrm{CaCO}_{3}$ particles in the presence of $\mathrm{O}_{2} / \mathrm{NO}_{2}$ mixture was much higher than that without $\mathrm{O}_{2}$ (Yu et al., 2018). The synergy of $\mathrm{NO}_{2}$ and $\mathrm{O}_{2}$, which involved mechanisms such as chain reactions, resulted in much faster sulfate formation than the sum of the reaction rates with $\mathrm{NO}_{2}$ and with $\mathrm{O}_{2}$ alone. These reports show the usefulness of single-particle Raman spectroscopy in studying the multiphase formation of particulate sulfate and nitrate. It is worth mentioning that degradation of organo-sulfate has been proposed to produce particulate inorganic sulfate recently (R. Xu et al., 2020), and organo-sulfate functional groups are also Raman-active (Bondy et al., 2018). Raman spectroscopy may find applications in the study of organo-sulfates.

\subsection{Multiphase formation of SOA}

Most of the organic compounds are Raman-active, though some of them may not have strong signals. Some generate fluorescence in general orders of magnitude stronger than Raman emissions, masking useful Raman features of particles. The characteristic peaks of a single organic compound are generally more than that of an inorganic one due to its 
complex molecular vibration modes, and the reaction products may further complicate spectra analysis. Therefore, investigation on the multiphase formation of SOA by Raman spectroscopy is limited. However, though identifying the molecular nature of the products is difficult, single-particle Raman spectroscopy can provide useful information during secondary organic aerosol (SOA) formation. For example, Lee et al. (2008b) observed a gradually elevating baseline in Raman spectra during acid-catalyzed octanol uptake by levitated sulfuric acid particles at $10 \% \mathrm{RH}$ but not at $50 \% \mathrm{RH}$ (Lee et al., 2008b). Though the speciation of products could not be resolved, the increasing fluorescence is evident, attributable to the formed SOA in the particles. Using an EDB, Chan and Chan (2011) examined the dependence of nonanal on the presence of hydrophilic and hydrophobic organics in acidic mixed organic-sulfuric-acid particles. The presence of hydrophobic organic materials (oleic acid and its reaction products with sulfuric acid) enhanced SOA formation by reactive uptake of nonanal, likely through an enhanced dissolution of nonanal in the particles (Chan and Chan, 2011). In contrast, levoglucosan, a hydrophilic organic, did not increase the uptake coefficient of nonanal. It is suggested that acid-catalyzed reactive uptake should be examined with the explicit consideration of the role of particle-phase organics that are either initially present or accumulated as a reaction product. Using micro-Raman, Olson et al. (2019) investigated the uptake of isoprene epoxydiol (IEPOX) by $\alpha$-pinene SOA/toluene SOA-coated AS particles (Olson et al., 2019). Before the uptake, both coated AS particles show core-shell morphology. $v(\mathrm{~N}-\mathrm{H})$ and $v\left(\mathrm{SO}_{4}^{2-}\right)$ were found at $\sim 3200$ and $\sim 976 \mathrm{~cm}^{-1}$ in the particle core, while strong $v(\mathrm{C}-\mathrm{H})$ at $2800-3000 \mathrm{~cm}^{-1}$ and other moderate/weak stretches of $\mathrm{C}-\mathrm{H}$ were found in the shell region. After the uptake, $v(\mathrm{C}-\mathrm{H})$ and $v\left(\mathrm{RO}-\mathrm{SO}_{3}\right)$ were found in the particle core, indicating $\mathrm{SOA}$ formation, such as organo-sulfate. No organo-sulfate was detected in shell regions of both types of particles, although decreases in $v(\mathrm{C}-\mathrm{H})$ peak were apparent. Generally, Raman analysis is useful for kinetic analysis of reactions (e.g., measuring uptake coefficients), but it is challenging to reveal complicated mechanisms due to the limited molecular identification. For better examining the reaction mechanism, deposited particles can be extracted for offline analysis using mass spectrometry (MS) (Li et al., 2008; Chan et al., 2013).

\subsection{Multiphase oxidation of aerosol particles}

In addition to reactive uptake of SOA precursors, singleparticle Raman spectroscopy has also been used to explore the uptake of oxidants by organic aerosol particles. So far, the reported studies are limited to ozonolysis. Raman spectroscopy is well suited in ozonolysis studies because the $\mathrm{C}=\mathrm{C}$ bonds and the peroxide groups are Ramanactive, and ozonolysis does not generate strongly fluorescent products. Using single-particle Raman spectroscopy, Lee and Chan (2007a) performed in situ observations of the particle mass, hygroscopicity, morphology of the oleic acid (Lee and Chan, 2007a), linolenic acid, and linoleic acid particles (Lee and Chan, 2007b) during ozonolysis. They found that low ozone concentration $(\sim 200-250 \mathrm{ppb})$ with a longer exposure period $(20 \mathrm{~h})$ favors autoxidation to form $\mathrm{C}=\mathrm{C}-\mathrm{C}=\mathrm{C}$ groups, but an extremely high ozone concentration $(\sim 10 \mathrm{ppm})$ at shorter exposure time $(2 \mathrm{~h})$ tends to form carboxylic acids $(\mathrm{C}=\mathrm{O})$, secondary ozonide $(\mathrm{O}-\mathrm{O})$, hydroxyalkyl hydroperoxide (O-H), etc. (Enami and Colussi, 2017; Qiu et al., 2020). Chu et al. (2019) further examined the interchangeability between ozone concentration and exposure time by studying ozonolysis of linoleic acid particles in a broader range of experimental conditions. They found the interchangeability holds at ozone exposure $\leq 500 \mathrm{ppbh}$ and $\left[\mathrm{O}_{3}\right] \leq 100 \mathrm{ppb}$ for the formation of autoxidation products containing conjugated diene structures but does not hold for the decay of parent linoleic acid or at higher $\left[\mathrm{O}_{3}\right](\mathrm{Chu}$ et al., 2019). These results indicate that extrapolating experimental results of the ozonolysis under high- $\left[\mathrm{O}_{3}\right]$ conditions to ambient levels should be carried out with caution. Single-particle Raman spectroscopy also enables us to infer the volatilization of some ozonolysis products. For example, Lee and Chan (2007b) found that the mass of oleic acid particles was observed to decrease with time while that of linoleic acid and linolenic acid increased on the contrary, which could be potentially explained by the different volatility of the ozonolysis products (Lee and Chan, 2007b). King et al. (2004) reported an optical tweezer study of ozonolysis of oleic acid and synthetic seawater droplets. They found clear Raman signatures indicating nonanoic acid and nonanal production, followed by their gradual disappearance, which is also likely due to the volatilization (King et al., 2004). Furthermore, Dennis-Smither et al. (2012) used optical tweezers to study the oxidation of oleic acid droplets containing an inorganic seed with a time resolution of $1 \mathrm{~s}$ to resolve the reactive loss of ozone and the evaporative loss of products. The oleic acid ozonolysis was completed in $\sim 3000 \mathrm{~s}$, but the decrease in droplet volume still lasts for an additional $\sim 5000 \mathrm{~s}$ due to the slow volatilization of the products (Dennis-Smither et al., 2012).

Chan and Chan (2012) studied the roles of the phase state and water content in the ozonolysis of maleic acid (MA) and AS mixed particles. Aqueous MA was found to be more reactive towards ozone than crystalline MA. Interestingly, they also found that higher water content favors more efficient ozonolysis, although the concentration of MA is accordingly lower (Chan and Chan, 2012). Furthermore, ozonolysis of optically trapped bioaerosol particles has also been reported. In general, lipids and proteins show distinct $v(\mathrm{C}-\mathrm{H})$ peaks at 2855 and $2928 \mathrm{~cm}^{-1}$, respectively (Kline and Treado, 1997; Rygula et al., 2013; Czamara et al., 2015). The ratio of these peaks can be thus used for inferring the different susceptibilities of lipids and proteins during ozonolysis oxidation (Gong et al., 2019). The products derived from oxidations such as carbonyls $\left(\mathrm{C}=\mathrm{O} ; \sim 1700 \mathrm{~cm}^{-1}\right.$ ) (Lee and Chan, 2007b) and 
oligomers of cysteine $\left(\mathrm{C}-\mathrm{S} ; \sim 662 \mathrm{~cm}^{-1}\right.$ ) (Movasaghi et al., 2007; Kampf et al., 2015) are also detected.

There are also studies exploring other organic surrogates of atmospheric aerosol with more complicated structures. For example, King et al. (2008) measured the uptake coefficients of ozone on fumarate and benzoate droplets (as a proxy of HULIS-containing aerosol) and $\alpha$-pinene droplets (a proxy of biogenic organic aerosol) (King et al., 2008). Different reaction products such as carbonate were identified in Raman spectra, though the chemical characterization is not comprehensive due to their volatility and the detection limits. The reaction of $\alpha$-pinene in the droplet phase was more than 1 order faster than in bulk aqueous solutions, likely due to more effective diffusion of ozone in the gas phase and more efficient mass accommodation at the air-droplet interface (King et al., 2008). Milsom et al. (2021) reported the ozonolysis of fatty-acid-soap mixed particles, using oleic acid and sodium oleate as models. In these particles, the strong interactions between the soap carboxylate and the carboxylic acid form crystalline structures (Milsom et al., 2021). Upon ozonolysis, the decay of $\mathrm{C}=\mathrm{C}\left(\sim 1600 \mathrm{~cm}^{-1}\right)$ was faster in liquid oleic acid droplets than crystalline oleic-acid-soap particles, although the crystalline structure was eventually broken by ozonolysis. Uraoka et al. (2017) studied the multiphase reactions of optically trapped soot particles with ozone and $\mathrm{OH}$ radicals. $\mathrm{C}=\mathrm{O}$ vibrations were observed under both ozone and $\mathrm{OH}$ exposure. The graphitic domain was suggested to undergo $\mathrm{OH}$ oxidation based on the increase in the ratio of the disorder (D) to the graphite $(\mathrm{G})$ domain from Raman spectra (Uraoka et al., 2017).

\subsection{Amine and ammonia reactions}

Ammonia and amines are the most abundant alkaline gases in the atmosphere. They play a significant role in new particle formation and buffering aerosol $\mathrm{pH}$ by neutralization of acidic particles (Kirkby et al., 2011; Almeida et al., 2013; Zhang et al., 2015; Kerminen et al., 2018; G. Zheng et al., 2020; Tian et al., 2022). There are three common types of reactions involving ammonia and amines: (1) neutralization reaction between acidic particles and ammonia or amines; (2) displacement of ammonia by amines from ammonium salt particles and vice versa from aminium salt particles; (3) reactions between ammonia or amines and dissolved dicarbonyls or between gaseous dicarbonyls and ammonium or aminium salt particles - both would result in the formation of colored compounds (i.e., brown carbon; $\mathrm{BrC}$ ).

Based on the strong vibration signal of the $\mathrm{C}-\mathrm{H}$ bond ( $\sim 2900 \mathrm{~cm}^{-1}$, sharp peak) from amine or aminium salts and the $\mathrm{N}-\mathrm{H}$ bond ( $2800-3300 \mathrm{~cm}^{-1}$, broad peak), the uptake of amine and ammonia can be easily studied using singleparticle Raman spectroscopy. Sauerwein and Chan (2017) explored the role of phase state in simultaneous uptake of ammonia and dimethylamine (DMA) by acidic particles (e.g., sulfuric acid and oxalic acid). Anhydrous acidic parti- cles were inert and took up DMA and ammonia presumably by adsorption and absorption only. The uptake rates of DMA and ammonia by aqueous acidic droplets were found to be comparable initially, but once the droplets were neutralized, the stronger base DMA displaced some of the particulate ammonium. On the other hand, if crystallization took place during the uptake, DMA uptake was inhibited, but continuous ammonia uptake gradually displaced the particle DMA ions.

Chan and Chan (2013) reported that the exchange reactions of ammonia/amine vapors in aqueous particles were reversible, and the exchange rates of aqueous particles were, in general, higher than those of their corresponding solid counterparts. Compared with crystalline solids (e.g., methylammonium sulfate), amorphous solid (e.g., diethylammonium sulfate) was found with a higher exchange rate, likely due to the less compact molecular structure (Chan and Chan, 2013). Chu and Chan (2017a, b) further examined the effect of a hydrophilic viscous organic surrogate and a hydrophobic organic coating on DMA uptake by AS. Both the viscous materials and the fresh and aged organic coating retarded DMA uptake by mass-transfer limitation (Chu and Chan, 2017a, b). The uptake of DMA by crystallized AS particles at $10 \%-$ $30 \% \mathrm{RH}$ resulted in the deliquescence of the particles, likely due to the presence of surface-adsorbed water (SAW) that promoted the dissolution of DMA. Once dimethylaminium sulfate is formed, it absorbs more water since it is more hygroscopic than AS and further promoted DMA uptake (Chu and Chan, 2017b). As crystalline solids are generally considered inert towards reactions, this finding indicates that SAW on crystals can serve as a medium to facilitate gas uptake.

$\mathrm{BrC}$ has attracted increasing attention due to its atmospheric abundance and capacity in regulating radiative balance (Laskin et al., 2015). The reactions between dicarbonyls and ammonium/aminium-containing salt particles can form BrC. Gen et al. (2018) investigated the multiphase uptake of glyoxal by ammonium-salt-containing particles using microRaman spectroscopy. They found a gradual elevation of the baseline, which was attributed to the formation of a fluorescent $\mathrm{BrC}$ (i.e., 2,2'-biimidazole, BI), based on offline analysis by UV-Vis spectroscopy and fluorescence spectroscopy (Gen et al., 2018). The reduction in ALW at low RH increases the glyoxal uptake rate via the enhanced saltingin effect and the BI formation rate by facilitating dehydration reactions. Mabato et al. (2019) examined glyoxal uptake by methylaminium-salt-containing particles. Although the salting-in effect was also found in methylaminium-saltcontaining particles, enhanced BI formation was not observed, likely due to the higher hygroscopicity of methylaminium salt (i.e., higher ALW content) than ammonium salt (Mabato et al., 2019).

\subsection{Photochemistry of aerosol particles}

A particular type of aerosol particle reaction that deserves special attention is photochemical reactions, which can be 
initiated by irradiation of the particles. Nitrate can be photolyzed under atmospheric irradiation $(\lambda>290 \mathrm{~nm})$. Nitrate photolysis proceeds via three channels: one produces $\mathrm{NO}_{2}$ and $\mathrm{OH}$ radicals, another produces $\mathrm{NO}_{2}^{-}$and $\mathrm{O}\left({ }^{3} \mathrm{P}\right)$, and the last generates $\mathrm{ONOO}^{-}$(Scharko et al., 2014; Benedict et al., 2017). The third channel's quantum yield is considered negligible compared with the former two since $\mathrm{ONOO}^{-}$is unstable (Mabato et al., 2022). Particulate nitrate photolysis in the atmospheric has been reviewed by a recent paper (Gen et al., 2022). It has been reported that $\mathrm{NO}_{2}^{-}$and $\mathrm{ONOO}^{-}$peaks increased, but $\mathrm{NO}_{3}^{-}$peaks decreased in the Raman spectra of acoustically levitated nitrate particles irradiated by UV (Tobon et al., 2017). $\mathrm{NO}_{2}$ does not have a large absorption cross-section, but it may be hydrolyzed into $\mathrm{NO}_{2}^{-}$(Tobon et al., 2017; Seng et al., 2018; Gómez Castaño et al., 2019). Most nitrate photolysis products are oxidants, so their ability to initiate oxidation reactions has also been explored (Gen et al., 2019b, c; R. Zhang et al., 2020). The production of sulfate via nitrate photolysis was discussed earlier. Recently, R. Zhang et al. (2021) reported a prominent formate production by glyoxal oxidation during particulate nitrate photolysis, instead of the more commonly found oxalic acids in the oxidation of glyoxal in bulk solutions (R. Zhang et al., 2021; Tan et al., 2009; Zhang et al., 2019). Furthermore, Liang et al. (2021) studied nitrate photolysis in particles containing sucrose, which was used as a surrogate for atmospheric viscous organics. They found that the viscosity of the particle did not reduce the nitrate photolysis rate, but it limited the diffusion of gaseous products (e.g., $\mathrm{NO}_{x}, \mathrm{NO}_{y}$ ) from nitrate photolysis. At a high sucrose fraction and $30 \% \mathrm{RH}$, the production of these gaseous products and the particles' viscosity transformed the droplets into "hollow and enlarged" semi-solid particles. Very recently, Zhang et al (2022) reported an enhanced decay of glyoxal by a factor of 12 in $\mathrm{NH}_{4} \mathrm{NO}_{3} /$ glyoxal premixed particles, compared to that under dark condition, due to nitrate photolysis and $\mathrm{BrC}$ induced (e.g., imidazole-2-carboxaldehyde) photosensitization. Using a Raman microscope, a new organic phase was observed in irradiated $\mathrm{NH}_{4} \mathrm{NO}_{3}$ /glyoxal droplets with no noticeable degradation under prolonged photooxidation, which may contribute to atmospheric SOA formation.

Size dependence of nitrate photochemistry has been recently reported, based on single-particle Raman spectroscopy. Tobon et al. (2017) studied the photolysis of acoustically levitated nitrate particles $(40-80 \mu \mathrm{m})$ at $254 \mathrm{~nm}$ UV radiation. No change in Raman spectra was observed for $2 \mathrm{~h}$. In contrast, smaller particles $(5-8 \mu \mathrm{m})$ trapped optically yielded various Raman peaks of nitrate photolysis products (Tobon et al., 2017; Gómez Castaño et al., 2019). The slow photolysis in the larger nitrate particles was attributed to the self-inhibited surface process. Additionally, an uneven distribution of $\mathrm{NO}_{2}^{-}$inside the smaller particle was also observed through Raman mapping (Gómez Castaño et al., 2019). Organics in the aerosol particle may also decompose under light. For example, Parmentier et al. (2021) reported pho- todegradation of optically trapped oleic acid droplets under 532 and $660 \mathrm{~nm}$ irradiation, likely initiated by photosensitization. However, they cautioned that the degradation loss of optically trapped particles might be due to artifacts (Parmentier et al., 2021). The photo-decay of light-absorbing particulate matter is also of great interest in understanding its fate in the atmosphere. However, there are very limited studies of atmospheric photochemical reactions using Raman spectroscopy, partly because of the need for complementary chemical speciation for detailed mechanistic studies.

\section{Enhanced Raman spectroscopy}

Though Raman spectroscopy has been used to study physical and chemical processes of atmospheric particles, most of the studies used large particles (dozens of microns) and focused on lab-generated particles with a few representative components. That is primarily because of the intrinsic diffraction limitation of Raman measurements that the laser beam cannot be effectively focused to a spot smaller than its wavelength and thus limits the detection of particles to larger than 1 micron or so. Fluorescence can also be a complication in some chemical systems.

Various methods have been developed to improve the Raman signal-to-noise ratios and the spatial resolution in other research fields such as material science and biology. Surfaceenhanced Raman spectroscopy (SERS) and tip-enhanced Raman spectroscopy (TERS) have been recently employed in atmospheric research. SERS and TERS enhance Raman emissions by the localized surface plasmon resonances using noble metal nanoparticles (NPs) to provide hot spots near the contacting sites between the analyte and NPs (Ault and Axson, 2017). According to the SERS electromagnetic (EM) enhancement theory, the relationship between the SERS intensity $(I)$ and the local EM strength $(E)$ follows $I \propto|E|^{4}$. The relationship between $E$ and the distance between NPs and analytes $(D)$ is described as $E \propto(1 / D)$ (Zhou et al., 2015). Hence, maximizing $E$ and minimizing $D$ without inducing significant perturbation to the sample is the primary goal. In addition to this physical enhancement based on the electromagnetic field, Raman signals can also be enhanced chemically. Specifically, molecular/ionic species can attach to the surface of NPs, distorting the molecular structure and increasing the absorption cross-section. Consequently, the Raman signal of an adsorbed species can be enhanced, potentially accompanied by a peak shift (Craig et al., 2015; Gen and Chan, 2017).

SERS enables the measurements of single particles smaller than 1 micron. Craig et al. (2015) found that the signals from individual submicron (down to $0.6 \mu \mathrm{m}$ ) particles could be effectively detected with intensity enhancement (Craig et al., 2015). Furthermore, Tirella et al. (2018) extended the SERS detection to the accumulation mode (800$150 \mathrm{~nm}$ ) particles (Tirella et al., 2018). Sun et al. (2019a, 
b) reported a size-resolved (covering both coarse mode and accumulation mode) SERS characterization study of atmospheric particles sampled during haze events (Sun et al., 2019a, b). More recently, Kunihisa et al. (2020) reported sensitive SERS measurement of Aitken mode particles $(<100 \mathrm{~nm})$ by combining a condensational growth tube sampler (CGT) and a SERS substrate for directly sampling (Kunihisa et al., 2020). The wide analytical range of particle size enables SERS to be a potentially powerful tool in studying ambient particulate matters (Steer et al., 2016; Vejpongsa et al., 2017; Chen et al., 2021).

Some species including components of microorganisms (Tahir et al., 2020), microplastics (G. Xu et al., 2020), crystalline silica (Zheng et al., 2018), the fine structure of organics (Craig et al., 2015; Fu et al., 2017; Gen et al., 2018), and even some Raman-active inorganic salts at very low concentration (Saniel et al., 2019) are invisible in normal Raman due to their weak Raman activities. However, they could be detected with a SERS substrate. The sensitive detection by SERS can provide valuable insight into particle transformations and emission sources (Vejpongsa et al., 2017; Ghosal and Wall, 2019; Lee et al., 2019). However, the enhancement factor of SERS is not constant. It strongly depends on the distribution and quantity of noble metal NPs and the hot spots over the substrate, making quantitative analysis difficult. Many attempts have been made to explore preferable and tunable substrate for generalizable atmospheric particle detection (G. Xu et al., 2020; Cheng et al., 2021), but still more progress is needed in the future.

The most common SERS application uses particles deposited on SERS substrates, relying on the hot spot located beneath the analyte particles. Recently, some studies create innovative interactions between particulate analytes and SERS NPs to enhance SERS detections. Wei et al. (2018) used 4-mercaptobenzoic acid-functionalized AuNPs as $\mathrm{pH}$ nanoprobes and internal SERS substrate and found the existence of a stable $\mathrm{pH}$ gradient inside aqueous particles (Wei et al., 2018). Hence, the assumption of homogeneous mixing might not always be correct, and $\mathrm{pH}$ predictions by thermodynamic model might underestimate the acidity of interfacial layers of particles, which is crucial for multiphase uptake or surface reactions. As a further investigation of the SERS $\mathrm{pH}$ nanoprobe, Q. Huang et al. (2021) reported that the pH distribution inside aerosol particles is affected by the internal distribution of ions, which may depend on the ionic speciation. While sodium tends to reside in the bulk of the particle, leading to a high centroid $\mathrm{pH}, \mathrm{pH}$ distributes more evenly in ammonium salt droplets because ammonium has a higher surface propensity than sodium (Q. Huang et al., 2021).

Gen and Chan (2017) developed an electrospray system (ES-SERS) to deposit SERS NPs onto the surface of the analyte particle and found that this technique can selectively enhance the peak intensity of the species located at surface layers such as surface-adsorbed water (Gen and Chan, 2017) and organic coatings (Gen et al., 2019a). In a typical micro-
Raman setup, the objective is above the analyte particle. When the analyte particle is deposited on the SERS substrate, the SERS hot spots are located beneath the particle. In other words, upon laser irradiation from the top, the photons generated by excitation need to pass through the particle with a refractive index greater than air, which would scatter or absorb light and thus reduce the signals received by the Raman microscope. In contrast, ES-SERS hot spots are created on the surface of the particle using electrospray. This configuration reduces the loss of photons and affords greater enhancement in the Raman intensity (Fig. 5). Besides, as the SERS effect is much more prominent near the hot spots, the location of the hot spot determines what part of the particle will be probed. Therefore, while typical SERS substrate collects enhanced Raman signals from the substrate-particle interface, the ES-SERS can provide information from the gas-particle interface, where many atmospheric multiphase processes occur. Sivaprakasam et al. (2017) and Sivaprakasam and Hart (2021) reported real-time SERS measurements of electrostatically trapped particles containing analyte molecules and NPs as internally mixed liquid particles or coating on solid particles (Sivaprakasam et al., 2017; Sivaprakasam and Hart, 2021). The interaction between NPs and analyte increased due to more contact areas than between an aerosol particle and a substrate.

Similarly, TERS can produce enhanced Raman signals even from particles in the nucleation mode. TERS is a combination of an atomic force microscope (AFM) and a Raman spectrometer. In general, the AFM determines the topography of a single deposited particle by detecting the interaction force between the AFM tip and the surface of the analytes. In a typical TERS setup, the AFM tip is coated with noble metal particles. An enhanced Raman signal is generated when the tip is interacting with analytes under laser excitation (Rodriguez et al., 2015). The lack of chemical information of AFM is complemented by SERS. Thus, TERS enables simultaneous characterization of particulate topography and surface species of submicron particles at a high spatial resolution (Ofner et al., 2016). TERS also has the potential for quantitative analysis since the quantity and configuration of hot spots on the tip are constant.

\section{Bioaerosols}

Bioaerosols have attracted increasing attention worldwide due to the COVID-19 epidemic. Studies using normal Raman/SERS for offline detection of biological samples (FélixRivera and Hernández-Rivera, 2012; Mosier-Boss, 2017) and real-time sensing of bioaerosol (Huffman et al., 2020) have been reviewed in detail elsewhere. Bioaerosols have various Raman-active components such as phosphate lipid $\left(\delta(=\mathrm{C}-\mathrm{H}), \sim 1268 \mathrm{~cm}^{-1} ; v(\mathrm{C}-\mathrm{H}), \sim 2855 \mathrm{~cm}^{-1}\right)$, protein (amides bands, $\sim 1260, \sim 1600, \sim 1660 \mathrm{~cm}^{-1}$; C-C backbone stretching in $\beta$-sheet proteins, $\sim 983 \mathrm{~cm}^{-1} ; v(\mathrm{C}-\mathrm{H})$, 


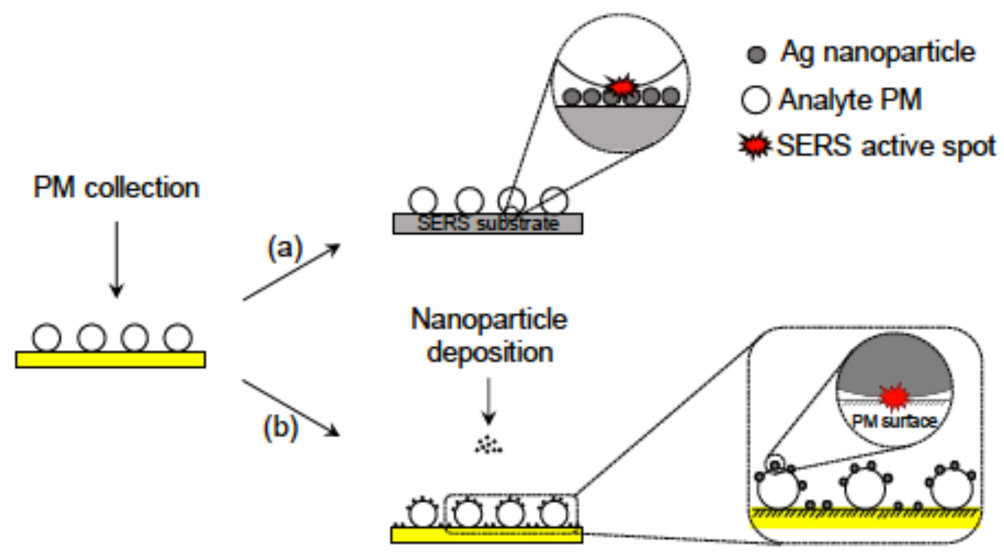

Figure 5. Schematic illustration of (a) a conventional SERS substrate approach and (b) the ES-SERS approach (Gen and Chan, 2017).

$\sim 2928 \mathrm{~cm}^{-1}$ ), and nucleic acids (e.g., adenine, $\sim 735 \mathrm{~cm}^{-1}$ ) (Socrates, 2004; Rygula et al., 2013; Talari et al., 2015). However, Raman signals from bioaerosol particles are generally weak. To amplify the signals, bioaerosol particles are trapped or deposited onto a substrate for longer integration time (Laucks et al., 2000; Sengupta et al., 2005; Tripathi et al., 2009; C. Wang et al., 2015; Redding et al., 2015b; Ai et al., 2020). Using a higher-energy laser can also enhance Raman intensity, but it may cause damage to bioaerosol (e.g., fragmentation) (Gong et al., 2017). On this basis, SERS is more suitable than normal Raman spectroscopy. SERS can also quench the fluorescence generated by biomolecules such as tryptophan and tyrosine (Gong et al., 2017).

In general, there are two strategies of single-particle SERS of bioaerosols: (1) directly sampling bioaerosols on a SERS substrate; (2) moving mixed colloids of SERS NPs and bioaerosols onto a glass substrate, followed by drying. While the former is more convenient without complex pretreatments (Tahir et al., 2020), the latter enables flexible modification of NP properties. For example, the functionalized surface of NPs with tag molecules (e.g., antibody), so-called label-based SERS (Liu et al., 2010), was used for detecting specific biomaterials with high reproducibility. Label-free SERS refers to that without tag molecules, such as $\mathrm{Au} @ \mathrm{Ag}$ (i.e., Au core with $\mathrm{Ag}$ shell). In general, by simply mixing, NPs distribute on biomaterials without specific interactions, and the SERS reproducibility is limited. However, by coating AgNPs on the cell wall of bacteria $(\mathrm{H}$. Zhou et al., 2014, 2015), SERS enhancement was $\sim 30$-folds reproducibly higher than simply mixed colloid-bacterial suspension. Furthermore, the discrimination of live and dead bacteria was possible. NPs can be directly formed inside some specific bacteria via bio-reduction for probing the intercellular structure (Jarvis et al., 2008). Overall, SERS can be an innovative tool in bioaerosol characterization, but the antibacterial effect of NPs and heat effect due to excitation laser should be considered (Mosier-Boss, 2017). More examples of bioaerosol detection can be found in a recent review (Liu et al., 2017).

\section{Future directions}

This review paper has shown examples of single-particle Raman spectroscopy in studying atmospheric processes. Overall, the water content, phase state, morphology, and chemical composition of single particles during physical and chemical processes at controlled RH can be monitored in situ. Hygroscopicity and phase behaviors covering a wide range of RH after these processes can also be comprehensively assessed by performing evaporation-humidification cycle measurements (Chan et al., 2006; Chan and Chan, 2007; Liu et al., 2008; Chen et al., 2020). Although fluorescence may exist in some particles, it could be potentially reduced or even eliminated by (1) using longer excitation wavelengths (e.g., 785 and $1064 \mathrm{~nm}$ ), (2) employing SERS/TERS, and (3) photo-bleaching of fluorescent substances under UV-Vis illumination (Gong et al., 2017). There are many other innovative studies built on trapping, manipulating, and observing multi-particles via Raman (Mitchem and Reid, 2008; Davies, 2019), such as measuring the viscosity and diffusion coefficient (Power et al., 2013; Nakajima et al., 2021), probing reaction (Aardahl et al., 1998; Rkiouak et al., 2014), and phase transition (Richards et al., 2020). Based on these functions and research progress, we would like to provide the following suggestions on future directions.

- Combining other techniques with single-particle Raman spectroscopy. Raman spectroscopy is non-destructive, so incorporating other spectroscopic techniques for characterizing the same particle is possible. Vibrational sum frequency generation spectroscopy (SFG), Fourier transform infrared spectroscopy (FTIR), and fluorescence spectroscopy, which are also non-destructive, could be complementary to Raman in probing the chemical composition of single particles. Recently, novel 
combination of EDB and mass spectrometry was reported, which can directly introduce the trapped particle for mass spectrometry analysis (Jacobs et al., 2017; Birdsall et al., 2018; Willis et al., 2020). Adoption of this technique with Raman to form an EDBRaman system with subsequent MS analysis is relatively straightforward. For optical properties, UV-Vis spectroscopy could be a promising choice (Jones et al., 2021). While general laser-based MDR can easily bleach light-absorbing molecules, a recent study reported that MDR modes under broadband excitation can measure refractive index (RI) of light-sensitive samples (Price et al., 2020). Such MDR measurements can complement in situ Raman spectroscopy for chemical characterization. Additionally, SERS and TERS are emerging useful approaches, but current SERS and TERS methods for atmospheric research mainly use bare NPs. The direct contact of NPs to analyte molecules can potentially induce chemical enhancement, which could complicate the identification of the phase transition and functional groups (Craig et al., 2015; Gen and Chan, 2017). To remove the chemical enhancement, future studies on chemically inert NPs such as shell-isolated nanoparticle-enhanced Raman spectroscopy (SHINERS) are suggested (Li et al., 2010; Anema et al., 2011).

- Multiphase reaction studies based on single-particle Raman spectroscopy. Single-particle Raman spectroscopy enables investigations of various atmospheric reactions, including those in surface-adsorbed water for solids, mixed-phase particles (solid, aqueous, organic), supersaturated droplets, atmospheric aging of bioaerosols, and ultrafast reactions. For solid particles (e.g., crystalline, mineral dust), multiphase reactions can be mediated by surface-adsorbed water layers and may result in phase transition, turning the particle into liquid for further reactions (Kuwata and Martin, 2012; Chu and Chan, 2017b; Zhao et al., 2018; Yu et al., 2018; Gen et al., 2019a). Probing heterogenous reactions on the particle surface is possible via ES-SERS, TERS, and normal Raman imaging. As particle constituents can be unevenly distributed (e.g., in LLPS) within a single particle, chemistry may not be the same between the bulk and the surface layers (Wei et al., 2018; Olson et al., 2019; Qiu et al., 2019; Q. Huang et al., 2021; Lam et al., 2021). The studies of the atmospheric processing of pre-existing particles to form secondary aerosols can be further extended to the aging of bioaerosols (Gong et al., 2019). Using pulse laser for excitation, timeresolved resonance Raman spectroscopy (TR3) can be a promising tool in probing short-lived reactive intermediates (e.g., triplet state molecules). In particular, it helps deepen our understanding in ultrafast reactions or initiation steps of typical reactions (Sahoo et al., 2011; Collins et al., 2018).

- Particle size and temperature effects. Many publications report single-particle Raman spectroscopy studies under different environmental conditions, including $\mathrm{RH}$ and gas concentration. However, how experimental conditions such as temperature and particle size affect kinetics and products in multiphase reactions remains ambiguous. For example, various pathways and kinetic parameters have been proposed to explain particulate sulfate formation in winter haze events in northern China (Chan and Yao, 2008; Su et al., 2020; Liu et al., 2021). However, most studies are based on experimental results at room temperature or $298 \mathrm{~K}$. Further exploration with respect to the effect of low temperature on the properties of the particles and multiphase sulfate chemistry is still warranted. Employing a temperature-controlled cold-plate flow-cell-Raman system for deposited single particles (Wheeler et al., 2015; Mael et al., 2019; Roy et al., 2020), investigations of temperature-dependent reaction kinetics can be easily achieved. Temperature control in a small levitation chamber is also more convenient than in a flow tube or smog chamber. To date, almost all single-particle Raman studies involve supermicron particles. While equilibrium measurements are not sensitive to size (assuming the Kelvin effect is considered), kinetic analysis is often size-dependent. Hence, uptake coefficients for multiphase reactions are usually reported and are restricted to experimental conditions that gas- and liquid-phase transport are not the ratelimiting step. The size detection limit of single-particle Raman spectroscopy can be extended to sub-10 $\mu \mathrm{m}$ with high sensitivity using high-energy excitation laser and tighter optical focusing. The effect of temperature and particle size on multiphase chemistry should be further investigated using long integration time, novel optical configuration (e.g., confocal micro-Raman), and SERS/TERS. Although it is challenging to study single submicron particles by Raman spectroscopy regularly, Raman characterization of a collection of single submicron particles is feasible. 
Appendix A

Table A1. Major Raman peaks of atmospherically relevant species.

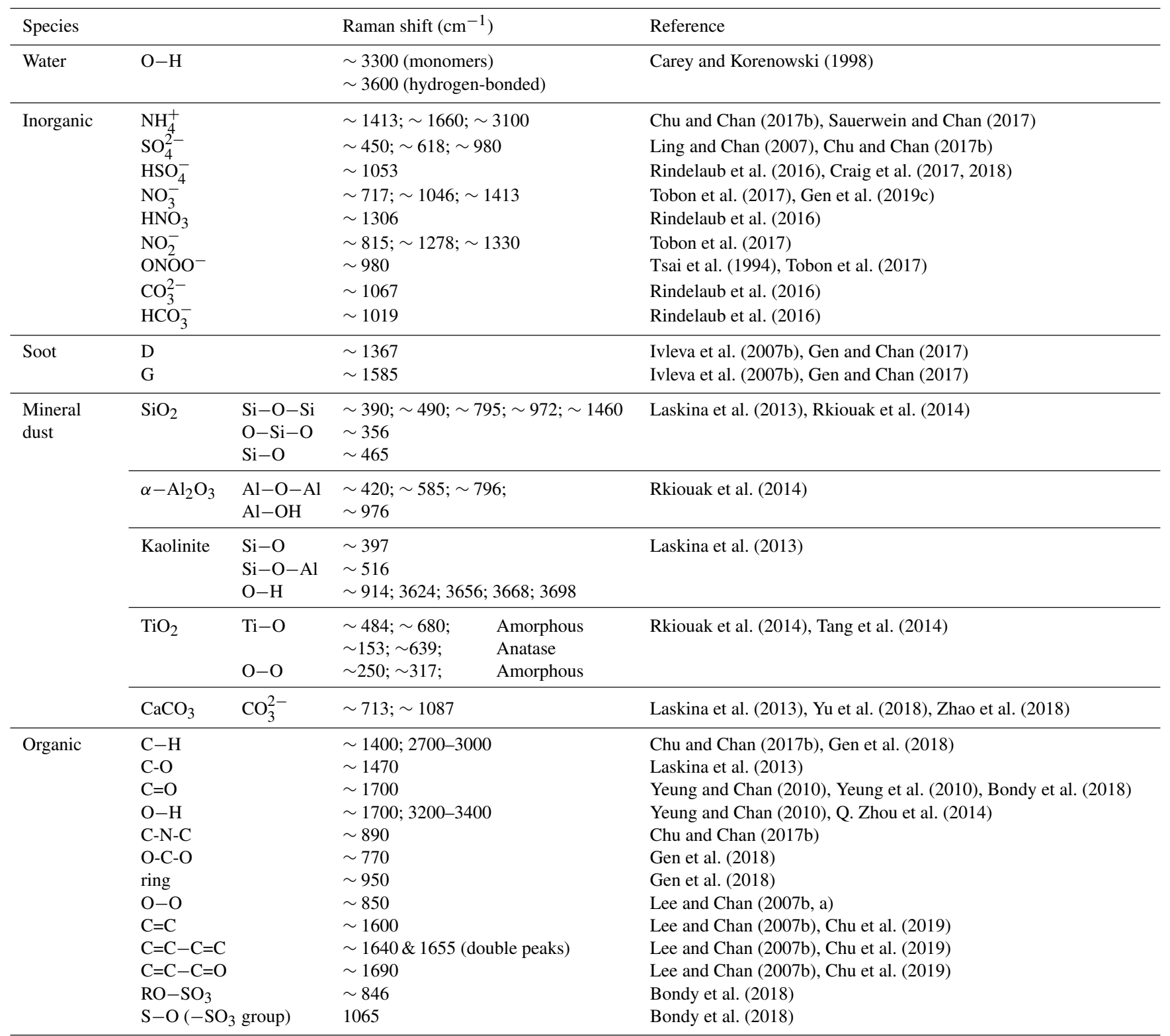

Data availability. All datasets are provided in Appendix A.

Author contributions. ZL and CKC conceptualized the work. $\mathrm{ZL}, \mathrm{YC}, \mathrm{MG}$, and $\mathrm{CKC}$ prepared the original draft and contributed to the review and editing.
Competing interests. The contact author has declared that neither they nor their co-authors have any competing interests.

Disclaimer. Publisher's note: Copernicus Publications remains neutral with regard to jurisdictional claims in published maps and institutional affiliations. 
Acknowledgements. We gratefully acknowledge the support from the National Natural Science Foundation of China (grant nos. 41905122, 42075100, and 41875142), the Hong Kong Research Grants Council (grant no. 11302318), the Japan Science and Technology Agency (JST) Fusion Oriented Research for disruptive Science and Technology program (grant no. 20352853), and the Japan Society for the Promotion of Science (JSPS) Grants-in-Aid for Early-Career Scientists (grant no. 21K17876).

Financial support. This research has been supported by the National Natural Science Foundation of China (grant nos. 41905122, 42075100, and 41875142); the Research Grants Council, University Grants Committee (grant no. 11302318); the Japan Science and Technology Agency (grant no. 20352853); and the Japan Society for the Promotion of Science (grant no. 21K17876).

Review statement. This paper was edited by Jason Surratt and reviewed by two anonymous referees.

\section{References}

Aardahl, C. L. and Davis, E. J. P. B.: Gas/Aerosol Chemical Reactions in the $\mathrm{NaOH}-\mathrm{SO} 2-\mathrm{H} 2 \mathrm{O}$ System, Appl. Spectrosc., 50, 71-77, 1996.

Aardahl, C. L., Widmann, J. F., and Davis, E. J.: Raman Analysis of Chemical Reactions Resulting from the Collision of MicrometerSized Particles, Appl. Spectrosc., 52, 47-53, 1998.

Ai, Y., Alali, H., Pan, Y.-L., Videen, G., and Wang, C.: Singleparticle optical-trapping raman spectroscopy for the detection and identification of aerosolized airborne biological particles, Meas. Sci. Technol., 32, 5, https://doi.org/10.1088/13616501/abd5f1, 2020.

Akimoto, H., Hoshino, M., Inoue, G., Sakamaki, F., Washida, N., and Okuda, M.: Design and characterization of the evacuable and bakable photochemical smog chamber, Environ. Sci. Technol., 13, 471-475, 1979.

Almeida, J., Schobesberger, S., Kürten, A., Ortega, I. K., Kupiainen-Määttä, O., Praplan, A. P., Adamov, A., Amorim, A., Bianchi, F., and Breitenlechner, M.: Molecular understanding of sulphuric acid-amine particle nucleation in the atmosphere, Nature, 502, 359-363, 2013.

Anema, J. R., Li, J.-F., Yang, Z.-L., Ren, B., and Tian, Z.-Q.: Shell-Isolated Nanoparticle-Enhanced Raman Spectroscopy: Expanding the Versatility of Surface-Enhanced Raman Scattering, Annu. Rev. Anal. Chem., 4, 129-150, https://doi.org/10.1146/annurev.anchem.111808.073632, 2011.

Angle, K. J., Neal, E. E., and Grassian, V. H.: Enhanced Rates of Transition-Metal-Ion-Catalyzed Oxidation of S(IV) in Aqueous Aerosols: Insights into Sulfate Aerosol Formation in the Atmosphere, Environ. Sci. Technol., 55, 10291-10299, https://doi.org/10.1021/acs.est.1c01932, 2021.

Ao, J., Feng, Y., Wu, S., Wang, T., Ling, J., Zhang, L., and Ji, M.: Rapid, 3D Chemical Profiling of Individual Atmospheric Aerosols with Stimulated Raman Scattering Microscopy, Small Methods, 4, 1900600, https://doi.org/10.1002/smtd.201900600, 2020 .
Ashkin, A.: Acceleration and Trapping of Particles by Radiation Pressure, Phys. Rev. Lett., 24, 156-159, https://doi.org/10.1103/PhysRevLett.24.156, 1970.

Ashkin, A. and Dziedzic, J.: Observation of optical resonances of dielectric spheres by light scattering, Appl. Opt., 20, 1803-1814, 1981.

Ashraf, H., Guo, Y., Wang, N., Pang, S., and Zhang, Y.-H.: Hygroscopicity of Hofmeister Salts and Glycine Aerosols-Salt Specific Interactions, J. Phys. Chem. A, 125, 1589-1597, 2021.

Ault, A. P. and Axson, J. L.: Atmospheric Aerosol Chemistry: Spectroscopic and Microscopic Advances, Anal. Chem., 89, 430-452, https://doi.org/10.1021/acs.analchem.6b04670, 2017.

Ault, A. P., Guasco, T. L., Baltrusaitis, J., Ryder, O. S., Trueblood, J. V., Collins, D. B., Ruppel, M. J., Cuadra-Rodriguez, L. A., Prather, K. A., and Grassian, V. H.: Heterogeneous Reactivity of Nitric Acid with Nascent Sea Spray Aerosol: Large Differences Observed between and within Individual Particles, J. Phys. Chem. Lett., 5, 2493-2500, 10.1021/jz5008802, 2014.

Bao, F., Li, M., Zhang, Y., Chen, C., and Zhao, J.: Photochemical Aging of Beijing Urban PM2.5: HONO Production, Environ. Sci. Technol., 52, 6309-6316, https://doi.org/10.1021/acs.est.8b00538, 2018.

Batonneau, Y., Sobanska, S., Laureyns, J., and Bremard, C.: Confocal Microprobe Raman Imaging of Urban Tropospheric Aerosol Particles, Environ. Sci. Technol., 40, 1300-1306, https://doi.org/10.1021/es051294x, 2006.

Behnke, W., Holländer, W., Koch, W., Nolting, F., and Zetzsch, C.: A smog chamber for studies of the photochemical degradation of chemicals in the presence of aerosols (1967), Atmos. Environ., 22, 1113-1120, 1988.

Benedict, K. B., McFall, A. S., and Anastasio, C.: Quantum Yield of Nitrite from the Photolysis of Aqueous Nitrate above $300 \mathrm{~nm}$, Environ. Sci. Technol., 51, 4387-4395, https://doi.org/10.1021/acs.est.6b06370, 2017.

Bertram, A. K., Martin, S. T., Hanna, S. J., Smith, M. L., Bodsworth, A., Chen, Q., Kuwata, M., Liu, A., You, Y., and Zorn, S. R.: Predicting the relative humidities of liquid-liquid phase separation, efflorescence, and deliquescence of mixed particles of ammonium sulfate, organic material, and water using the organic-to-sulfate mass ratio of the particle and the oxygen-tocarbon elemental ratio of the organic component, Atmos. Chem. Phys., 11, 10995-11006, https://doi.org/10.5194/acp-11-109952011, 2011.

Birdsall, A. W., Krieger, U. K., and Keutsch, F. N.: Electrodynamic balance-mass spectrometry of single particles as a new platform for atmospheric chemistry research, Atmos. Meas. Tech., 11, 3347, https://doi.org/10.5194/amt-11-33-2018, 2018.

Bondy, A. L., Craig, R. L., Zhang, Z., Gold, A., Surratt, J. D., and Ault, A. P.: Isoprene-Derived Organosulfates: Vibrational Mode Analysis by Raman Spectroscopy, AcidityDependent Spectral Modes, and Observation in Individual Atmospheric Particles, J. Phys. Chem. A, 122, 303-315, https://doi.org/10.1021/acs.jpca.7b10587, 2018.

Boyer, H. C., Gorkowski, K., and Sullivan, R. C.: In Situ $\mathrm{pH}$ Measurements of Individual Levitated Microdroplets Using Aerosol Optical Tweezers, Anal. Chem., 92, 1089-1096, https://doi.org/10.1021/acs.analchem.9b04152, 2020. 
Braban, C. F., Carroll, M. F., Styler, S. A., and Abbatt, J. P.: Phase transitions of malonic and oxalic acid aerosols, J. Phys. Chem. A, 107, 6594-6602, 2003.

Brunamonti, S., Krieger, U. K., Marcolli, C., and Peter, T.: Redistribution of black carbon in aerosol particles undergoing liquidliquid phase separation, Geophys. Res. Lett., 42, 2532-2539, 2015.

Buajarern, J., Mitchem, L., and Reid, J. P.: Characterizing Multiphase Organic/Inorganic/Aqueous Aerosol Droplets, J. Phys. Chem. A, 111, 90540-9061, https://doi.org/10.1021/jp074366a, 2007a.

Buajarern, J., Mitchem, L., and Reid, J. P.: Characterizing the Formation of Organic Layers on the Surface of Inorganic/Aqueous Aerosols by Raman Spectroscopy, J. Phys. Chem. A, 111, 11852-11859, https://doi.org/10.1021/jp075021v, 2007b.

Cai, C. and Zhao, C.: Optical levitation measurement on hygroscopic behaviour and SVOC vapour pressure of single organic/inorganic aqueous aerosol, Atmos. Environ., 189, 50-60, https://doi.org/10.1016/j.atmosenv.2018.06.040, 2018.

Carey, D. M. and Korenowski, G. M.: Measurement of the Raman spectrum of liquid water, J. Chem. Phys., 108, 2669-2675, 1998.

Chan, C. K. and Yao, X.: Air pollution in mega cities in China, Atmos. Environ., 42, 1-42, https://doi.org/10.1016/j.atmosenv.2007.09.003, 2008.

Chan, C. K., Flagan, R. C., and Seinfeld, J. H.: Resonance structures in elastic and Raman scattering from microspheres, Appl. Opt., 30, 459-467, https://doi.org/10.1364/AO.30.000459, 1991.

Chan, C. K., Flagan, R. C., and Seinfeld, J. H.: Water activities of $\mathrm{NH}_{4} \mathrm{NO}_{3} /\left(\mathrm{NH}_{4}\right)_{2} \mathrm{SO}_{4}$ solutions, Atmos. Environ. A-Gen., 26, 1661-1673, https://doi.org/10.1016/0960-1686(92)90065-S, 1992.

Chan, K. M., Huang, D. D., Li, Y. J., Chan, M. N., Seinfeld, J. H., and Chan, C. K.: Oligomeric products and formation mechanisms from acid-catalyzed reactions of methyl vinyl ketone on acidic sulfate particles, J. Atmos. Chem., 70, 1-18, 2013.

Chan, L. P. and Chan, C. K.: Enhanced Reactive Uptake of Nonanal by Acidic Aerosols in the Presence of Particle-Phase Organics, Aerosol Sci. Tech., 45, 872-883, https://doi.org/10.1080/02786826.2011.567314, 2011.

Chan, L. P. and Chan, C. K.: Roles of the Phase State and Water Content in Ozonolysis of Internal Mixtures of Maleic Acid and Ammonium Sulfate Particles, Aerosol Sci. Tech., 46, 781-793, https://doi.org/10.1080/02786826.2012.665514, 2012.

Chan, L. P. and Chan, C. K.: Role of the aerosol phase state in ammonia/amines exchange reactions, Environ. Sci. Technol., 47, 5755-5762, 2013.

Chan, M. N. and Chan, C. K.: Mass transfer effects on the hygroscopic growth of ammonium sulfate particles with a water-insoluble coating, Atmos. Environ., 41, 4423-4433, https://doi.org/10.1016/j.atmosenv.2007.01.047, 2007.

Chan, M. N., Choi, M. Y., Ng, N. L., and Chan, C. K.: Hygroscopicity of Water-Soluble Organic Compounds in Atmospheric Aerosols: Amino Acids and Biomass Burning Derived Organic Species, Environ. Sci. Technol., 39, 1555-1562, https://doi.org/10.1021/es0495841, 2005.

Chan, M. N., Lee, A. K., and Chan, C. K.: Responses of ammonium sulfate particles coated with glutaric acid to cyclic changes in relative humidity: Hygroscopicity and Raman characterization, Environ. Sci. Technol., 40, 6983-6989, 2006.
Chang, P., Chen, Z., Zhang, Y., and Liu, Y.: Direct measurement of aerosol $\mathrm{pH}$ in individual malonic acid and citric acid droplets under different relative humidity conditions via Raman spectroscopy, Chemosphere, 241, 124960, https://doi.org/10.1016/j.chemosphere.2019.124960, 2020a.

Chang, P., Gao, X., Cai, C., Ma, J., and Zhang, Y.: Effect of waiting time on the water transport kinetics of magnesium sulfate aerosol at gel-forming relative humidity using optical tweezers, Spectrochim. Acta A, 228, 117727, https://doi.org/10.1016/j.saa.2019.117727, 2020b.

Charan, S. M., Huang, Y., and Seinfeld, J. H.: Computational Simulation of Secondary Organic Aerosol Formation in Laboratory Chambers, Chem. Rev., 119, 11912-11944, https://doi.org/10.1021/acs.chemrev.9b00358, 2019.

Chen, H., Duan, F., Du, J., Yin, R., Zhu, L., Dong, J., He, K., Sun, Z., and Wang, S.: Surface-enhanced Raman scattering for mixing state characterization of individual fine particles during a haze episode in Beijing, China, J. Environ. Sci., 104, 216-224, https://doi.org/10.1016/j.jes.2020.12.008, 2021.

Chen, X., Chu, Y., Lee, A. K., Gen, M., Kasthuriarachchi, N. Y., Chan, C. K., and Li, Y. J.: Relative humidity history affects hygroscopicity of mixed particles of glyoxal and reduced nitrogenous species, Environ. Sci. Technol., 54, 7097-7106, 2020.

Cheng, H., Dong, X., Yang, Y., Feng, Y., Wang, T., Tahir, M. A., Zhang, L., and Fu, H.: Au nanoring arrays as surface enhanced Raman spectroscopy substrate for chemical component study of individual atmospheric aerosol particle, J. Environ. Sci., 100, 11 17, https://doi.org/10.1016/j.jes.2020.07.003, 2021.

Cheng, Y., Zheng, G., Wei, C., Mu, Q., Zheng, B., Wang, Z., Gao, M., Zhang, Q., He, K., Carmichael, G., Pöschl, U., and Su, H.: Reactive nitrogen chemistry in aerosol water as a source of sulfate during haze events in China, Science Advances, 2, e1601530, https://doi.org/10.1126/sciadv.1601530, 2016.

Choi, M. Y. and Chan, C. K.: The Effects of Organic Species on the Hygroscopic Behaviors of Inorganic Aerosols, Environ. Sci. Technol., 36, 2422-2428, https://doi.org/10.1021/es0113293, 2002.

Chu, Y. and Chan, C. K.: Role of oleic acid coating in the heterogeneous uptake of dimethylamine by ammonium sulfate particles, Aerosol Sci. Tech., 51, 988-997, https://doi.org/10.1080/02786826.2017.1323072, 2017a.

Chu, Y. and Chan, C. K.: Reactive Uptake of Dimethylamine by Ammonium Sulfate and Ammonium SulfateSucrose Mixed Particles, J. Phys. Chem. A, 121, 206-215, https://doi.org/10.1021/acs.jpca.6b10692, 2017 b.

Chu, Y., Sauerwein, M., and Chan, C. K.: Hygroscopic and phase transition properties of alkyl aminium sulfates at low relative humidities, Phys. Chem. Chem. Phys., 17, 19789-19796, 2015.

Chu, Y., Cheng, T. F., Gen, M., Chan, C. K., Lee, A. K. Y., and Chan, M. N.: Effect of Ozone Concentration and Relative Humidity on the Heterogeneous Oxidation of Linoleic Acid Particles by Ozone: An Insight into the Interchangeability of Ozone Concentration and Time, ACS Earth and Space Chemistry, 3, 779-788, https://doi.org/10.1021/acsearthspacechem.9b00002, 2019.

Ciavatta, L.: The Specific Interaction Theory in Evaluating Ionic Equilibria, Ann. Chim.-Rome, 70, 551--562, 1980.

Coddens, E. M., Angle, K. J., and Grassian, V. H.: Titration of Aerosol pH through Droplet Coalescence, J. Phys. Chem. Lett., 
10, 4476-4483, https://doi.org/10.1021/acs.jpclett.9b00757, 2019.

Cohen, L., Quant, M. I., and Donaldson, D. J.: Real-Time Measurements of $\mathrm{pH}$ Changes in Single, Acoustically Levitated Droplets Due to Atmospheric Multiphase Chemistry, ACS Earth and Space Chemistry, 4, 854-861, https://doi.org/10.1021/acsearthspacechem.0c00041, 2020.

Collins, D. B., Hems, R. F., Zhou, S., Wang, C., Grignon, E., Alavy, M., Siegel, J. A., and Abbatt, J. P. D.: Evidence for Gas-Surface Equilibrium Control of Indoor Nitrous Acid, Environ. Sci. Technol., 52, 12419-12427, https://doi.org/10.1021/acs.est.8b04512, 2018.

Cotterell, M. I., Mason, B. J., Carruthers, A. E., Walker, J. S., OrrEwing, A. J., and Reid, J. P.: Measurements of the evaporation and hygroscopic response of single fine-mode aerosol particles using a Bessel beam optical trap, Phys. Chem. Chem. Phys., 16, 2118-2128, 2014.

Craig, R. L., Bondy, A. L., and Ault, A. P.: Surface Enhanced Raman Spectroscopy Enables Observations of Previously Undetectable Secondary Organic Aerosol Components at the Individual Particle Level, Anal. Chem., 87, 7510-7514, https://doi.org/10.1021/acs.analchem.5b01507, 2015.

Craig, R. L., Nandy, L., Axson, J. L., Dutcher, C. S., and Ault, A. P.: Spectroscopic Determination of Aerosol pH from Acid-Base Equilibria in Inorganic, Organic, and Mixed Systems, J. Phys. Chem. A, 121, 5690-5699, https://doi.org/10.1021/acs.jpca.7b05261, 2017.

Craig, R. L., Peterson, P. K., Nandy, L., Lei, Z., Hossain, M. A., Camarena, S., Dodson, R. A., Cook, R. D., Dutcher, C. S., and Ault, A. P.: Direct Determination of Aerosol pH: Size-Resolved Measurements of Submicrometer and Supermicrometer Aqueous Particles, Anal. Chem., 90, 11232-11239, https://doi.org/10.1021/acs.analchem.8b00586, 2018.

Cruz, C. N. and Pandis, S. N.: Deliquescence and Hygroscopic Growth of Mixed Inorganic-Organic Atmospheric Aerosol, Environ. Sci. Technol., 34, 4313-4319, https://doi.org/10.1021/es9907109, 2000.

Cui, X., Tang, M., Wang, M., and Zhu, T.: Water as a probe for $\mathrm{pH}$ measurement in individual particles using micro-Raman spectroscopy, Anal. Chim. Acta, 1186, 339089, https://doi.org/10.1016/j.aca.2021.339089, 2021.

Czamara, K., Majzner, K., Pacia, M. Z., Kochan, K., Kaczor, A., and Baranska, M.: Raman spectroscopy of lipids: a review, J. Raman. Spectrosc., 46, 4-20, 2015.

Davies, J. F.: Mass, charge, and radius of droplets in a linear quadrupole electrodynamic balance, Aerosol Sci. Tech., 53, 309320, https://doi.org/10.1080/02786826.2018.1559921, 2019.

Davies, J. F. and Wilson, K. R.: Raman Spectroscopy of Isotopic Water Diffusion in Ultraviscous, Glassy, and Gel States in Aerosol by Use of Optical Tweezers, Anal. Chem., 88, 23612366, https://doi.org/10.1021/acs.analchem.5b04315, 2016.

Davies, J. F., Haddrell, A. E., Rickards, A. M. J., and Reid, J. P.: Simultaneous Analysis of the Equilibrium Hygroscopicity and Water Transport Kinetics of Liquid Aerosol, Anal. Chem., 85, 5819-5826, https://doi.org/10.1021/ac4005502, 2013.

Davis, E. J. and Ray, A.: Single aerosol particle size and mass measurements using an electrodynamic balance, J. Colloid Interf. Sci., 75, 566-576, 1980.
Dennis-Smither, B. J., Hanford, K. L., Kwamena, N.-O. A., Miles, R. E. H., and Reid, J. P.: Phase, Morphology, and Hygroscopicity of Mixed Oleic Acid/Sodium Chloride/Water Aerosol Particles before and after Ozonolysis, J. Phys. Chem. A, 116, 6159-6168, https://doi.org/10.1021/jp211429f, 2012.

Duporté, G., Riva, M., Parshintsev, J., Heikkinen, E., Barreira, L. M. F., Myllys, N., Heikkinen, L., Hartonen, K., Kulmala, M., Ehn, M., and Riekkola, M.-L.: Chemical Characterization of Gas- and Particle-Phase Products from the Ozonolysis of $\alpha$-Pinene in the Presence of Dimethylamine, Environ. Sci. Technol., 51, 56025610, https://doi.org/10.1021/acs.est.6b06231, 2017.

Efremov, E. V., Ariese, F., and Gooijer, C.: Achievements in resonance Raman spectroscopy: Review of a technique with a distinct analytical chemistry potential, Anal. Chim. Acta, 606, 119-134, 2008.

Enami, S. and Colussi, A. J.: Criegee Chemistry on Aqueous Organic Surfaces, J. Phys. Chem. Lett., 8, 1615-1623, https://doi.org/10.1021/acs.jpclett.7b00434, 2017.

Eom, H.-J., Gupta, D., Cho, H.-R., Hwang, H. J., Hur, S. D., Gim, Y., and Ro, C.-U.: Single-particle investigation of summertime and wintertime Antarctic sea spray aerosols using low$\mathrm{Z}$ particle EPMA, Raman microspectrometry, and ATR-FTIR imaging techniques, Atmos. Chem. Phys., 16, 13823-13836, https://doi.org/10.5194/acp-16-13823-2016, 2016.

Falgayrac, G., Siepka, D., Stefaniak, E. A., Penel, G., and Sobanska, S.: Influence of collecting substrate on the Raman imaging of micron-sized particles, Anal. Chim. Acta, 1014, 41-49, https://doi.org/10.1016/j.aca.2018.02.015, 2018.

Félix-Rivera, H. and Hernández-Rivera, S. P.: Raman Spectroscopy Techniques for the Detection of Biological Samples in Suspensions and as Aerosol Particles: A Review, Sens. Imaging, 13, 125, https://doi.org/10.1007/s11220-011-0067-0, 2012.

Fu, Y., Kuppe, C., Valev, V. K., Fu, H., Zhang, L., and Chen, J.: Surface-Enhanced Raman Spectroscopy: A Facile and Rapid Method for the Chemical Component Study of Individual Atmospheric Aerosol, Environ. Sci. Technol., 51, 6260-6267, https://doi.org/10.1021/acs.est.6b05910, 2017.

Gen, M. and Chan, C. K.: Electrospray surface-enhanced Raman spectroscopy (ES-SERS) for probing surface chemical compositions of atmospherically relevant particles, Atmos. Chem. Phys., 17, 14025-14037, https://doi.org/10.5194/acp-17-140252017, 2017.

Gen, M., Huang, D. D., and Chan, C. K.: Reactive Uptake of Glyoxal by Ammonium-Containing Salt Particles as a Function of Relative Humidity, Environ. Sci. Technol., 52, 6903-6911, https://doi.org/10.1021/acs.est.8b00606, 2018.

Gen, M., Kunihisa, R., Matsuki, A., and Chan, C. K.: Electrospray surface-enhanced Raman spectroscopy (ESSERS) for studying organic coatings of atmospheric aerosol particles, Aerosol Sci. Tech., 53, 760-770, https://doi.org/10.1080/02786826.2019.1597964, 2019a.

Gen, M., Zhang, R., Huang, D. D., Li, Y., and Chan, C. K.: Heterogeneous Oxidation of $\mathrm{SO}_{2}$ in Sulfate Production during Nitrate Photolysis at $300 \mathrm{~nm}$ : Effect of $\mathrm{pH}$, Relative Humidity, Irradiation Intensity, and the Presence of Organic Compounds, Environ. Sci. Technol., 53, 8757-8766, https://doi.org/10.1021/acs.est.9b01623, 2019b.

Gen, M., Zhang, R., Huang, D. D., Li, Y., and Chan, C. K.: Heterogeneous $\mathrm{SO}_{2}$ Oxidation in Sulfate Formation by Photoly- 
sis of Particulate Nitrate, Environ. Sci. Tech. Let., 6, 86-91, https://doi.org/10.1021/acs.estlett.8b00681, 2019c.

Gen, M., Zhang, R., Li, Y., and Chan, C. K.: Multiphase Photochemistry of Iron-Chloride Containing Particles as a Source of Aqueous Chlorine Radicals and Its Effect on Sulfate Production, Environ. Sci. Technol., 54, 9862-9871, https://doi.org/10.1021/acs.est.0c01540, 2020.

Gen, M., Zhang, R., and Chan, C. K.: Nitrite/Nitrous Acid Generation from the Reaction of Nitrate and Fe(II) Promoted by Photolysis of Iron-Organic Complexes, Environ. Sci. Technol., 55, 15715-15723, https://doi.org/10.1021/acs.est.1c05641, 2021.

Gen, M., Liang, Z., Zhang, R., Mabato, B. R. G., and Chan, C. K.: Particulate nitrate photolysis in the atmosphere, Environ. Sci.Atmos., D1EA00087J, https://doi.org/10.1039/D1EA00087J, 2022

George, I. J. and Abbatt, J. P.: Heterogeneous oxidation of atmospheric aerosol particles by gas-phase radicals, Nat. Chem., 2, 713-722, https://doi.org/10.1038/nchem.806, 2010.

Ghosal, S. and Wall, S.: Identifying regional soil as the potential source of $\mathrm{PM}_{2.5}$ particulate matter on air filters collected in Imperial Valley, California - A Raman micro-spectroscopy study, Environ. Pollut., 253, 181-189, https://doi.org/10.1016/j.envpol.2019.07.004, 2019.

Gómez Castaño, J. A., Boussekey, L., Verwaerde, J. P., Moreau, M., and Tobón, Y. A.: Enhancing Double-Beam Laser Tweezers Raman Spectroscopy (LTRS) for the Photochemical Study of Individual Airborne Microdroplets, Molecules, 24, 3325, https://doi.org/10.3390/molecules24183325, 2019.

Gong, Z., Pan, Y.-L., Videen, G., and Wang, C.: The temporal evolution process from fluorescence bleaching to clean Raman spectra of single solid particles optically trapped in air, Chem. Phys. Lett., 689, 100-104, https://doi.org/10.1016/j.cplett.2017.09.064, 2017.

Gong, Z., Pan, Y.-L., Videen, G., and Wang, C.: Optical trapping and manipulation of single particles in air: Principles, technical details, and applications, J. Quant. Spectrosc. Ra., 214, 94-119, https://doi.org/10.1016/j.jqsrt.2018.04.027, 2018a.

Gong, Z., Pan, Y.-L., Videen, G., and Wang, C.: Optical trappingRaman spectroscopy (OT-RS) with embedded microscopy imaging for concurrent characterization and monitoring of physical and chemical properties of single particles, Anal. Chim. Acta, 1020, 86-94, 2018b.

Gong, Z., Pan, Y.-L., Videen, G., and Wang, C.: Chemical reactions of single optically trapped bioaerosols in a controlled environment, Aerosol Sci. Tech., 53, 853-859, https://doi.org/10.1080/02786826.2019.1621984, 2019.

Gorkowski, K., Donahue, N. M., and Sullivan, R. C.: Emulsified and Liquid-Liquid Phase-Separated States of $\alpha$-Pinene Secondary Organic Aerosol Determined Using Aerosol Optical Tweezers, Environ. Sci. Technol., 51, 12154-12163, https://doi.org/10.1021/acs.est.7b03250, 2017.

Gorkowski, K., Donahue, N. M., and Sullivan, R. C.: Aerosol Optical Tweezers Constrain the Morphology Evolution of LiquidLiquid Phase-Separated Atmospheric Particles, Chem, 6, 204 220, https://doi.org/10.1016/j.chempr.2019.10.018, 2020.

Heine, N., Arata, C., Goldstein, A. H., Houle, F. A., and Wilson, K. R.: Multiphase Mechanism for the Production of Sulfuric Acid from $\mathrm{SO}_{2}$ by Criegee Intermediates Formed During the Heterogeneous Reaction of Ozone with Squalene, J. Phys. Chem.
Lett., 9, 3504-3510, https://doi.org/10.1021/acs.jpclett.8b01171, 2018.

Huang, Q., Wei, H., Marr, L. C., and Vikesland, P. J.: Direct Quantification of the Effect of Ammonium on Aerosol Droplet pH, Environ. Sci. Technol., 55, 778-787, https://doi.org/10.1021/acs.est.0c07394, 2021.

Huang, Y., Mahrt, F., Xu, S., Shiraiwa, M., Zuend, A., and Bertram, A. K.: Coexistence of three liquid phases in individual atmospheric aerosol particles, P. Natl. Acad. Sci. USA, 118, e2102512118, https://doi.org/10.1073/pnas.2102512118, 2021.

Huffman, J. A., Perring, A. E., Savage, N. J., Clot, B., Crouzy, B., Tummon, F., Shoshanim, O., Damit, B., Schneider, J., Sivaprakasam, V., Zawadowicz, M. A., Crawford, I., Gallagher, M., Topping, D., Doughty, D. C., Hill, S. C., and Pan, Y.: Real-time sensing of bioaerosols: Review and current perspectives, Aerosol Sci. Tech., 54, 465-495, https://doi.org/10.1080/02786826.2019.1664724, 2020.

Ishizaka, S., Yamamoto, C., and Yamagishi, H.: Liquid-Liquid Phase Separation of Single Optically Levitated Water-Ionic Liquid Droplets in Air, J. Phys. Chem. A, 125, 7716-7722, https://doi.org/10.1021/acs.jpca.1c06130, 2021.

Ivleva, N. P., McKeon, U., Niessner, R., and Pöschl, U.: Raman Microspectroscopic Analysis of Size-Resolved Atmospheric Aerosol Particle Samples Collected with an ELPI: Soot, HumicLike Substances, and Inorganic Compounds, Aerosol Sci. Tech., 41, 655-671, https://doi.org/10.1080/02786820701376391, 2007a.

Ivleva, N. P., Messerer, A., Yang, X., Niessner, R., and Pöschl, U.: Raman Microspectroscopic Analysis of Changes in the Chemical Structure and Reactivity of Soot in a Diesel Exhaust Aftertreatment Model System, Environ. Sci. Technol., 41, 37023707, https://doi.org/10.1021/es0612448, $2007 \mathrm{~b}$.

Jacobs, M. I., Davies, J. F., Lee, L., Davis, R. D., Houle, F., and Wilson, K. R.: Exploring Chemistry in Microcompartments Using Guided Droplet Collisions in a Branched Quadrupole Trap Coupled to a Single Droplet, Paper Spray Mass Spectrometer, Anal. Chem., 89, 12511-12519, https://doi.org/10.1021/acs.analchem.7b03704, 2017.

Jarvis, R. M., Law, N., Shadi, I. T., O’Brien, P., Lloyd, J. R., and Goodacre, R.: Surface-Enhanced Raman Scattering from Intracellular and Extracellular Bacterial Locations, Anal. Chem., 80, 6741-6746, https://doi.org/10.1021/ac800838v, 2008.

Jones, R. R., Hooper, D. C., Zhang, L., Wolverson, D., and Valev, V. K.: Raman techniques: Fundamentals and frontiers, Nanoscale Res. Lett., 14, 1-34, 2019.

Jones, S. H., Friederich, P., and Donaldson, D. J.: Photochemical Aging of Levitated Aqueous Brown Carbon Droplets, ACS Earth and Space Chemistry, 5, 749-754, https://doi.org/10.1021/acsearthspacechem.1c00005, 2021.

Kalume, A., Beresnev, L. A., Santarpia, J., and Pan, Y.-L.: Detection and characterization of chemical aerosol using laser-trapping single-particle Raman spectroscopy, Appl. Opt., 56, 6577-6582, https://doi.org/10.1364/AO.56.006577, 2017a.

Kalume, A., Zhu, E., Wang, C., Santarpia, J., and Pan, Y.L.: Position-resolved Raman spectra from a laser-trapped single airborne chemical droplet, Opt. Lett., 42, 5113-5116, https://doi.org/10.1364/OL.42.005113, 2017b.

Kalume, A., Wang, C., Santarpia, J., and Pan, Y.-L.: Liquid-liquid phase separation and evaporation of a laser-trapped organic- 
organic airborne droplet using temporal spatial-resolved Raman spectroscopy, Phys. Chem. Chem. Phys., 20, 19151-19159, https://doi.org/10.1039/C8CP02372G, 2018.

Kampf, C. J., Liu, F., Reinmuth-Selzle, K., Berkemeier, T., Meusel, H., Shiraiwa, M., and Pöschl, U.: Protein Cross-Linking and Oligomerization through Dityrosine Formation upon Exposure to Ozone, Environ. Sci. Technol., 49, 10859-10866, https://doi.org/10.1021/acs.est.5b02902, 2015.

Kang, E., Root, M. J., Toohey, D. W., and Brune, W. H.: Introducing the concept of Potential Aerosol Mass (PAM), Atmos. Chem. Phys., 7, 5727-5744, https://doi.org/10.5194/acp-7-5727-2007, 2007.

Keller, A. and Burtscher, H.: A continuous photo-oxidation flow reactor for a defined measurement of the SOA formation potential of wood burning emissions, J. Aerosol Sci., 49, 9-20, 2012.

Kerminen, V.-M., Chen, X., Vakkari, V., Petäjä, T., Kulmala, M., and Bianchi, F.: Atmospheric new particle formation and growth: review of field observations, Environ. Res. Lett., 13, 103003, https://doi.org/10.1016/j.jaerosci.2003.10.003, 2018.

King, M. D., Thompson, K. C., and Ward, A. D.: Laser tweezers Raman study of optically trapped aerosol droplets of seawater and oleic acid reacting with ozone: implications for cloud-droplet properties, J. Am. Chem. Soc., 126, 16710-16711, 2004.

King, M. D., Thompson, K. C., Ward, A. D., Pfrang, C., and Hughes, B. R.: Oxidation of biogenic and watersoluble compounds in aqueous and organic aerosol droplets by ozone: a kinetic and product analysis approach using laser Raman tweezers, Faraday Discuss., 137, 173-192, https://doi.org/10.1039/B702199B, 2008.

Kirkby, J., Curtius, J., Almeida, J., Dunne, E., Duplissy, J., Ehrhart, S., Franchin, A., Gagné, S., Ickes, L., and Kürten, A.: Role of sulphuric acid, ammonia and galactic cosmic rays in atmospheric aerosol nucleation, Nature, 476, 429-433, 2011.

Kline, N. J. and Treado, P. J.: Raman chemical imaging of breast tissue, J. Raman Spectrosc., 28, 119-124, 1997.

Knopf, D. A., Koop, T., Luo, B. P., Weers, U. G., and Peter, T.: Homogeneous nucleation of NAD and NAT in liquid stratospheric aerosols: insufficient to explain denitrification, Atmos. Chem. Phys., 2, 207-214, https://doi.org/10.5194/acp-2207-2002, 2002.

Knopf, D. A., Luo, B. P., Krieger, U. K., and Koop, T.: Thermodynamic Dissociation Constant of the Bisulfate Ion from Raman and Ion Interaction Modeling Studies of Aqueous Sulfuric Acid at Low Temperatures, J. Phys. Chem. A, 107, 4322-4332, https://doi.org/10.1021/jp027775+, 2003.

Kohli, R. K. and Davies, J. F.: Measuring the Chemical Evolution of Levitated Particles: A Study on the Evaporation of Multicomponent Organic Aerosol, Anal. Chem., 93, 12472-12479, 2021.

Krieger, U. K., Marcolli, C., and Reid, J. P.: Exploring the complexity of aerosol particle properties and processes using single particle techniques, Chem. Soc. Rev., 41, 6631-6662, 2012.

Kunihisa, R., Iwata, A., Gen, M., Chan, C. K., and Matsuki, A.: Application of SERS on the chemical speciation of individual Aitken mode particles after condensational growth, Aerosol Sci. Tech., 54, 826-836, https://doi.org/10.1080/02786826.2020.1730298, 2020.

Kuwata, M. and Martin, S. T.: Phase of atmospheric secondary organic material affects its reactivity, P. Natl. Acad. Sci. USA, 109, 17354-17359, https://doi.org/10.1073/pnas.1209071109, 2012.
Kwamena, N. O. A., Buajarern, J., and Reid, J. P.: Equilibrium Morphology of Mixed Organic/Inorganic/Aqueous Aerosol Droplets: Investigating the Effect of Relative $\mathrm{Hu}-$ midity and Surfactants, J. Phys. Chem. A, 114, 5787-5795, https://doi.org/10.1021/jp1003648, 2010.

Lam, H. K., Xu, R., Choczynski, J., Davies, J. F., Ham, D., Song, M., Zuend, A., Li, W., Tse, Y.-L. S., and Chan, M. N.: Effects of liquid-liquid phase separation and relative humidity on the heterogeneous $\mathrm{OH}$ oxidation of inorganic-organic aerosols: insights from methylglutaric acid and ammonium sulfate particles, Atmos. Chem. Phys., 21, 2053-2066, https://doi.org/10.5194/acp21-2053-2021, 2021.

Laskin, A., Laskin, J., and Nizkorodov, S. A.: Chemistry of atmospheric brown carbon, Chem. Rev., 115, 4335-4382, https://doi.org/10.1021/cr5006167, 2015.

Laskina, O., Young, M. A., Kleiber, P. D., and Grassian, V. H.: Infrared extinction spectroscopy and micro-Raman spectroscopy of select components of mineral dust mixed with organic compounds, J. Geophys. Res.-Atmos., 118, 6593-6606, https://doi.org/10.1002/jgrd.50494, 2013.

Laskina, O., Morris, H. S., Grandquist, J. R., Qin, Z., Stone, E. A., Tivanski, A. V., and Grassian, V. H.: Size Matters in the Water Uptake and Hygroscopic Growth of Atmospherically Relevant Multicomponent Aerosol Particles, J. Phys. Chem. A, 119, 44894497, https://doi.org/10.1021/jp510268p, 2015.

Laucks, M. L., Roll, G., Schweiger, G., and Davis, E. J.: PHYSICAL AND CHEMICAL (RAMAN) CHARACTERIZATION OF BIOAEROSOLS - POLLEN, J. Aerosol Sci., 31, 307-319, https://doi.org/10.1016/S0021-8502(99)00058-0, 2000.

Lee, A. K. Y. and Chan, C. K.: Single particle Raman spectroscopy for investigating atmospheric heterogeneous reactions of organic aerosols, Atmos. Environ., 41, 4611-4621, https://doi.org/10.1016/j.atmosenv.2007.03.040, 2007 a.

Lee, A. K. Y. and Chan, C. K.: Heterogeneous Reactions of Linoleic Acid and Linolenic Acid Particles with Ozone: Reaction Pathways and Changes in Particle Mass, Hygroscopicity, and Morphology, J. Phys. Chem. A, 111, 6285-6295, https://doi.org/10.1021/jp0718121, 2007b.

Lee, A. K. Y., Ling, T., and Chan, C. K.: Understanding hygroscopic growth and phase transformation of aerosols using single particle Raman spectroscopy in an electrodynamic balance, Faraday Discuss., 137, 245-263, 2008a.

Lee, A. K. Y., Li, Y. J., Lau, A. P. S., and Chan, C. K.: A ReEvaluation on the Atmospheric Significance of Octanal Vapor Uptake by Acidic Particles: Roles of Particle Acidity and GasPhase Octanal Concentration, Aerosol Sci. Tech., 42, 992-1000, https://doi.org/10.1080/02786820802382736, 2008b.

Lee, J. S., Ahn, Y., Kim, J., Kim, J., Nam, S. H., Yu, S.-C., Shin, H. H., Jung, T., Kim, E.-A., Suh, Y. D., Kim, H. W., and Park, H.R.: Chemical analysis of air pollutant particulate matters based on surface enhanced Raman spectroscopy (SERS), SPIE, 11082, 110822A, https://doi.org/10.1117/12.2529210, 2019.

Li, J. F., Huang, Y. F., Ding, Y., Yang, Z. L., Li, S. B., Zhou, X. S., Fan, F. R., Zhang, W., Zhou, Z. Y., Wu, D. Y., Ren, B., Wang, Z. L., and Tian, Z. Q.: Shell-isolated nanoparticle-enhanced Raman spectroscopy, Nature, 464, 392395, https://doi.org/10.1038/nature08907, 2010.

Li, R., Palm, B. B., Ortega, A. M., Hlywiak, J., Hu, W., Peng, Z., Day, D. A., Knote, C., Brune, W. H., de Gouw, J. A., and 
Jimenez, J. L.: Modeling the Radical Chemistry in an Oxidation Flow Reactor: Radical Formation and Recycling, Sensitivities, and the $\mathrm{OH}$ Exposure Estimation Equation, J. Phys. Chem. A, 119, 4418-4432, https://doi.org/10.1021/jp509534k, 2015.

Li, X., Gupta, D., Lee, J., Park, G., and Ro, C.-U.: Real-Time Investigation of Chemical Compositions and Hygroscopic Properties of Aerosols Generated from $\mathrm{NaCl}$ and Malonic Acid Mixture Solutions Using in Situ Raman Microspectrometry, Environ. Sci. Technol., 51, 263-270, https://doi.org/10.1021/acs.est.6b04356, 2017.

Li, X., Wu, L., Lee, J.-S., and Ro, C.-U.: Hygroscopic behavior and chemical reactivity of aerosols generated from mixture solutions of low molecular weight dicarboxylic acids and $\mathrm{NaCl}$, Phys. Chem. Chem. Phys., 23, 11052-11064, 2021.

Li, Y. J., Lee, A. K., Lau, A. P., and Chan, C. K.: Accretion reactions of octanal catalyzed by sulfuric acid: Product identification, reaction pathways, and atmospheric implications, Environ. Sci. Technol., 42, 7138-7145, 2008.

Liang, Z., Zhang, R., Gen, M., Chu, Y., and Chan, C. K.: Nitrate Photolysis in Mixed Sucrose-Nitrate-Sulfate Particles at Different Relative Humidities, J. Phys. Chem. A, 125, 3739-3747, https://doi.org/10.1021/acs.jpca.1c00669, 2021.

Ling, T. Y. and Chan, C. K.: Formation and Transformation of Metastable Double Salts from the Crystallization of Mixed Ammonium Nitrate and Ammonium Sulfate Particles, Environ. Sci. Technol., 41, 8077-8083, https://doi.org/10.1021/es071419t, 2007.

Ling, T. Y. and Chan, C. K.: Partial crystallization and deliquescence of particles containing ammonium sulfate and dicarboxylic acids, J. Geophys. Res.-Atmos., 113, D14205, https://doi.org/10.1029/2008JD009779, 2008.

Liu, T. and Abbatt, J. P.: An experimental assessment of the importance of S(IV) oxidation by hypohalous acids in the marine atmosphere, Geophys. Res. Lett., 47, e2019GL086465, https://doi.org/10.1029/2019GL086465, 2020.

Liu, T. and Abbatt, J. P. D.: Oxidation of sulfur dioxide by nitrogen dioxide accelerated at the interface of deliquesced aerosol particles, Nat. Chem., 13, 1173-1177, https://doi.org/10.1038/s41557-021-00777-0, 2021.

Liu, T., Wang, X., Hu, Q., Deng, W., Zhang, Y., Ding, X., Fu, X., Bernard, F., Zhang, Z., Lü, S., He, Q., Bi, X., Chen, J., Sun, Y., Yu, J., Peng, P., Sheng, G., and Fu, J.: Formation of secondary aerosols from gasoline vehicle exhaust when mixing with $\mathrm{SO}_{2}$, Atmos. Chem. Phys., 16, 675-689, https://doi.org/10.5194/acp16-675-2016, 2016.

Liu, T., Clegg, S. L., and Abbatt, J. P.: Fast oxidation of sulfur dioxide by hydrogen peroxide in deliquesced aerosol particles, P. Natl. Acad. Sci. USA, 117, 1354-1359, 2020.

Liu, T., Chan, A. W. H., and Abbatt, J. P. D.: Multiphase Oxidation of Sulfur Dioxide in Aerosol Particles: Implications for Sulfate Formation in Polluted Environments, Environ. Sci. Technol., 55, 4227-4242, https://doi.org/10.1021/acs.est.0c06496, 2021.

Liu, X., Knauer, M., Ivleva, N. P., Niessner, R., and Haisch, C.: Synthesis of Core-Shell Surface-Enhanced Raman Tags for Bioimaging, Anal. Chem., 82, 441-446, https://doi.org/10.1021/ac902573p, 2010.

Liu, Y. J., Zhu, T., Zhao, D. F., and Zhang, Z. F.: Investigation of the hygroscopic properties of $\mathrm{Ca}\left(\mathrm{NO}_{3}\right)_{2}$ and internally mixed $\mathrm{Ca}\left(\mathrm{NO}_{3}\right)_{2} / \mathrm{CaCO}_{3}$ particles by micro-Raman spectrometry, At- mos. Chem. Phys., 8, 7205-7215, https://doi.org/10.5194/acp-87205-2008, 2008.

Liu, Y., Zhou, H., Hu, Z., Yu, G., Yang, D., and Zhao, J.: Label and label-free based surface-enhanced Raman scattering for pathogen bacteria detection: A review, Biosens. Bioelectron., 94, 131-140, https://doi.org/10.1016/j.bios.2017.02.032, 2017.

Liu, Y., Wang, T., Fang, X., Deng, Y., Cheng, H., Bacha, A.-U.-R., Nabi, I., and Zhang, L.: Brown carbon: An underlying driving force for rapid atmospheric sulfate formation and haze event, Sci. Total Environ., 734, 139415, https://doi.org/10.1016/j.scitotenv.2020.139415, 2020.

Lu, J. W., Isenor, M., Chasovskikh, E., Stapfer, D., and Signorell, R.: Low-temperature Bessel beam trap for single submicrometer aerosol particle studies, Rev. Sci. Instrum., 85, 095107, https://doi.org/10.1063/1.4895118, 2014.

Ma, Q., Liu, C., Ma, J., Chu, B., and He, H.: A laboratory study on the hygroscopic behavior of $\mathrm{H}_{2} \mathrm{C}_{2} \mathrm{O}_{4}$ containing mixed particles, Atmos. Environ., 200, 34-39, https://doi.org/10.1016/j.atmosenv.2018.11.056, 2019a.

Ma, Q., Zhong, C., Liu, C., Liu, J., Ma, J., Wu, L., and He, H.: A Comprehensive Study about the Hygroscopic Behavior of Mixtures of Oxalic Acid and Nitrate Salts: Implication for the Occurrence of Atmospheric Metal Oxalate Complex, ACS Earth and Space Chemistry, 3, 1216-1225, https://doi.org/10.1021/acsearthspacechem.9b00077, 2019b.

Ma, S., Chen, Z., Pang, S., and Zhang, Y.: Observations on hygroscopic growth and phase transitions of mixed 1, 2, 6hexanetriol / $\left(\mathrm{NH}_{4}\right)_{2} \mathrm{SO}_{4}$ particles: investigation of the liquidliquid phase separation (LLPS) dynamic process and mechanism and secondary LLPS during the dehumidification, Atmos. Chem. Phys., 21, 9705-9717, https://doi.org/10.5194/acp21-9705-2021, 2021.

Mabato, B. R. G., Gen, M., Chu, Y., and Chan, C. K.: Reactive Uptake of Glyoxal by Methylaminium-Containing Salts as a Function of Relative Humidity, ACS Earth and Space Chemistry, 3, 150-157, https://doi.org/10.1021/acsearthspacechem.8b00154, 2019.

Mabato, B. R. G., Lyu, Y., Ji, Y., Li, Y. J., Huang, D. D., Li, X., Nah, T., Lam, C. H., and Chan, C. K.: Aqueous secondary organic aerosol formation from the direct photosensitized oxidation of vanillin in the absence and presence of ammonium nitrate, Atmos. Chem. Phys., 22, 273-293, https://doi.org/10.5194/acp22-273-2022, 2022.

Mael, L. E., Busse, H., and Grassian, V. H.: Measurements of Immersion Freezing and Heterogeneous Chemistry of Atmospherically Relevant Single Particles with Micro-Raman Spectroscopy, Anal. Chem., 91, 11138-11145, https://doi.org/10.1021/acs.analchem.9b01819, 2019.

Mael, L. E., Busse, H. L., Peiker, G., and Grassian, V. H.: Low-Temperature Water Uptake of Individual Marine and Biologically Relevant Atmospheric Particles Using MicroRaman Spectroscopy, J. Phys. Chem. A, 125, 9691-9699, https://doi.org/10.1021/acs.jpca.1c08037, 2021.

Marcolli, C. and Krieger, U. K.: Relevance of particle morphology for atmospheric aerosol processing, Trends in Chemistry, 2, 1-3, 2020.

Marsh, A., Miles, R. E. H., Rovelli, G., Cowling, A. G., Nandy, L., Dutcher, C. S., and Reid, J. P.: Influence of organic compound functionality on aerosol hygroscopicity: dicar- 
boxylic acids, alkyl-substituents, sugars and amino acids, Atmos. Chem. Phys., 17, 5583-5599, https://doi.org/10.5194/acp17-5583-2017, 2017.

Marsh, A., Rovelli, G., Miles, R. E. H., and Reid, J. P.: Complexity of Measuring and Representing the Hygroscopicity of Mixed Component Aerosol, J. Phys. Chem. A, 123, 1648-1660, https://doi.org/10.1021/acs.jpca.8b11623, 2019.

Mekic, M., Wang, Y., Loisel, G., Vione, D., and Gligorovski, S.: Ionic Strength Effect Alters the Heterogeneous Ozone Oxidation of Methoxyphenols in Going from Cloud Droplets to Aerosol Deliquescent Particles, Environ. Sci. Technol., 54, 12898-12907, https://doi.org/10.1021/acs.est.0c03648, 2020.

Meresman, H., Wills, J. B., Summers, M., McGloin, D., and Reid, J. P.: Manipulation and characterisation of accumulation and coarse mode aerosol particles using a Bessel beam trap, Phys. Chem. Chem. Phys., 11, 11333-11339, 2009.

Mikhailov, E., Vlasenko, S., Martin, S. T., Koop, T., and Pöschl, U.: Amorphous and crystalline aerosol particles interacting with water vapor: conceptual framework and experimental evidence for restructuring, phase transitions and kinetic limitations, Atmos. Chem. Phys., 9, 9491-9522, https://doi.org/10.5194/acp-9-94912009, 2009.

Miles, R. E. H., Walker, J. S., Burnham, D. R., and Reid, J. P.: Retrieval of the complex refractive index of aerosol droplets from optical tweezers measurements, Phys. Chem. Chem. Phys., 14, 3037-3047, https://doi.org/10.1039/C2CP23999J, 2012.

Milsom, A., Squires, A. M., Boswell, J. A., Terrill, N. J., Ward, A. D., and Pfrang, C.: An organic crystalline state in ageing atmospheric aerosol proxies: spatially resolved structural changes in levitated fatty acid particles, Atmos. Chem. Phys., 21, 1500315021, https://doi.org/10.5194/acp-21-15003-2021, 2021.

Mitchem, L. and Reid, J. P.: Optical manipulation and characterisation of aerosol particles using a single-beam gradient force optical trap, Chem. Soc. Rev., 37, 756-769, https://doi.org/10.1039/B609713H, 2008.

Mitchem, L., Buajarern, J., Hopkins, R. J., Ward, A. D., Gilham, R. J. J., Johnston, R. L., and Reid, J. P.: Spectroscopy of Growing and Evaporating Water Droplets: Exploring the Variation in Equilibrium Droplet Size with Relative Humidity, J. Phys. Chem. A, 110, 8116-8125, https://doi.org/10.1021/jp061135f, 2006.

Mosier-Boss, P. A.: Review on SERS of Bacteria, Biosensors, 7, 51, https://doi.org/10.3390/bios7040051, 2017.

Movasaghi, Z., Rehman, S., and Rehman, I. U.: Raman Spectroscopy of Biological Tissues, Appl. Spectrosc. Rev., 42, 493541, https://doi.org/10.1080/05704920701551530, 2007.

Nadler, K. A., Kim, P., Huang, D.-L., Xiong, W., and Continetti, R. E.: Water diffusion measurements of single charged aerosols using $\mathrm{H}_{2} \mathrm{O} / \mathrm{D}_{2} \mathrm{O}$ isotope exchange and Raman spectroscopy in an electrodynamic balance, Phys. Chem. Chem. Phys., 21, 1506215071, https://doi.org/10.1039/C8CP07052K, 2019.

Nakajima, R., Miura, A., Abe, S., and Kitamura, N.: Optical Trapping-Polarized Raman Microspectroscopy of Single Ethanol Aerosol Microdroplets: Droplet Size Effects on Rotational Relaxation Time and Viscosity, Anal. Chem., 93, 52185224, https://doi.org/10.1021/acs.analchem.0c05406, 2021.

Nishikida, K., Nishio, E., and Hannah, R. W.: Selected applications of modern FT-IR techniques, CRC Press, Routledge, 280 pp., ISBN 9780367448486, 2018.
Offroy, M., Moreau, M., Sobanska, S., Milanfar, P., and Duponchel, L.: Pushing back the limits of Raman imaging by coupling superresolution and chemometrics for aerosols characterization, Sci. Rep., 5, 12303, https://doi.org/10.1038/srep12303, 2015.

Ofner, J., Deckert-Gaudig, T., Kamilli, K. A., Held, A., Lohninger, H., Deckert, V., and Lendl, B.: Tip-Enhanced Raman Spectroscopy of Atmospherically Relevant Aerosol Nanoparticles, Anal. Chem., 88, 9766-9772, https://doi.org/10.1021/acs.analchem.6b02760, 2016.

Olson, N. E., Lei, Z., Craig, R. L., Zhang, Y., Chen, Y., Lambe, A. T., Zhang, Z., Gold, A., Surratt, J. D., and Ault, A. P.: Reactive Uptake of Isoprene Epoxydiols Increases the Viscosity of the Core of Phase-Separated Aerosol Particles, ACS Earth and Space Chemistry, 3, 1402-1414, https://doi.org/10.1021/acsearthspacechem.9b00138, 2019.

Pajunoja, A., Hu, W., Leong, Y. J., Taylor, N. F., Miettinen, P., Palm, B. B., Mikkonen, S., Collins, D. R., Jimenez, J. L., and Virtanen, A.: Phase state of ambient aerosol linked with water uptake and chemical aging in the southeastern US, Atmos. Chem. Phys., 16, 11163-11176, https://doi.org/10.5194/acp-16-111632016, 2016.

Pan, Y.-L., Hill, S. C., and Coleman, M.: Photophoretic trapping of absorbing particles in air and measurement of their single-particle Raman spectra, Opt. Express, 20, 5325-5334, https://doi.org/10.1364/OE.20.005325, 2012.

Parmentier, E. A., David, G., Arroyo, P. C., Bibawi, S., Esat, K., and Signorell, R.: Photochemistry of single optically trapped oleic acid droplets, J. Aerosol Sci., 151, 105660, https://doi.org/10.1016/j.jaerosci.2020.105660, 2021.

Parsons, M. T., Mak, J., Lipetz, S. R., and Bertram, A. K.: Deliquescence of malonic, succinic, glutaric, and adipic acid particles, J. Geophys. Res.-Atmos., 109, D06212, https://doi.org/10.1029/2003JD004075, 2004.

Peng, C., Chan, M. N., and Chan, C. K.: The Hygroscopic Properties of Dicarboxylic and Multifunctional Acids: Measurements and UNIFAC Predictions, Environ. Sci. Technol., 35, 44954501, https://doi.org/10.1021/es0107531, 2001.

Peng, Z. and Jimenez, J. L.: Radical chemistry in oxidation flow reactors for atmospheric chemistry research, Chem. Soc. Rev., 49, 2570-2616, https://doi.org/10.1039/C9CS00766K, 2020.

Pöschl, U.: Atmospheric Aerosols: Composition, Transformation, Climate and Health Effects, Angew. Chem. Int. Edit., 44, 75207540, https://doi.org/10.1002/anie.200501122, 2005.

Power, R., Simpson, S., Reid, J., and Hudson, A.: The transition from liquid to solid-like behaviour in ultrahigh viscosity aerosol particles, Chem. Sci., 4, 2597-2604, 2013.

Price, C. L., Bain, A., Wallace, B. J., Preston, T. C., and Davies, J. F.: Simultaneous Retrieval of the Size and Refractive Index of Suspended Droplets in a Linear Quadrupole Electrodynamic Balance, J. Phys. Chem. A, 124, 1811-1820, https://doi.org/10.1021/acs.jpca.9b10748, 2020.

Qin, Y., Ye, J., Ohno, P., Zhai, J., Han, Y., Liu, P., Wang, J., Zaveri, R. A., and Martin, S. T.: Humidity Dependence of the Condensational Growth of $\alpha$-Pinene Secondary Organic Aerosol Particles, Environ. Sci. Technol., 55, 14360-14369, https://doi.org/10.1021/acs.est.1c01738, 2021.

Qiu, J., Ishizuka, S., Tonokura, K., and Enami, S.: Interfacial vs Bulk Ozonolysis of Nerolidol, Environ. Sci. Technol., 53, 57505757, https://doi.org/10.1021/acs.est.9b00364, 2019. 
Qiu, J., Liang, Z., Tonokura, K., Colussi, A. J., and Enami, S.: Stability of Monoterpene-Derived $\alpha$-Hydroxyalkyl-Hydroperoxides in Aqueous Organic Media: Relevance to the Fate of Hydroperoxides in Aerosol Particle Phases, Environ. Sci. Technol., 54, 3890-3899, https://doi.org/10.1021/acs.est.9b07497, 2020.

Radić, N. and Prkić, A.: Historical remarks on the HendersonHasselbalch equation: its advantages and limitations and a novel approach for exact $\mathrm{pH}$ calculation in buffer region, Reviews in Anal. Chem., 31, 93-98, 2012.

Rafferty, A. and Preston, T. C.: Measuring the size and complex refractive index of an aqueous aerosol particle using electromagnetic heating and cavity-enhanced Raman scattering, Phys. Chem. Chem. Phys., 20, 17038-17047, https://doi.org/10.1039/C8CP02966K, 2018.

Redding, B. and Pan, Y.-L.: Optical trap for both transparent and absorbing particles in air using a single shaped laser beam, Opt. Lett., 40, 2798-2801, https://doi.org/10.1364/OL.40.002798, 2015.

Redding, B., Hill, S. C., Alexson, D., Wang, C., and Pan, Y.-L.: Photophoretic trapping of airborne particles using ultraviolet illumination, Opt. Express, 23, 3630-3639, https://doi.org/10.1364/OE.23.003630, 2015a.

Redding, B., Schwab, M. J., and Pan, Y.-1.: Raman spectroscopy of optically trapped single biological micro-particles, Sensors, 15, 19021-19046, 2015b.

Reid, J. P. and Mitchem, L.: LASER PROBING OF SINGLE-AEROSOL DROPLET DYNAMICS, Annu. Rev. Phys. Chem., 57, 245-271, https://doi.org/10.1146/annurev.physchem.57.032905.104621, 2006.

Renbaum-Wolff, L., Song, M., Marcolli, C., Zhang, Y., Liu, P. F., Grayson, J. W., Geiger, F. M., Martin, S. T., and Bertram, A. K.: Observations and implications of liquid-liquid phase separation at high relative humidities in secondary organic material produced by $\alpha$-pinene ozonolysis without inorganic salts, Atmos. Chem. Phys., 16, 7969-7979, https://doi.org/10.5194/acp16-7969-2016, 2016.

Richards, D. S., Trobaugh, K. L., Hajek-Herrera, J., Price, C. L., Sheldon, C. S., Davies, J. F., and Davis, R. D.: Ionmolecule interactions enable unexpected phase transitions in organic-inorganic aerosol, Science Advances, 6, eabb5643, https://doi.org/10.1126/sciadv.abb5643, 2020.

Rindelaub, J. D., Craig, R. L., Nandy, L., Bondy, A. L., Dutcher, C. S., Shepson, P. B., and Ault, A. P.: Direct Measurement of pH in Individual Particles via Raman Microspectroscopy and Variation in Acidity with Relative Humidity, J. Phys. Chem. A, 120, 911917, https://doi.org/10.1021/acs.jpca.5b12699, 2016.

Rkiouak, L., Tang, M., Camp, J., McGregor, J., Watson, I., Cox, R., Kalberer, M., Ward, A., and Pope, F.: Optical trapping and Raman spectroscopy of solid particles, Phys. Chem. Chem. Phys., 16, 11426-11434, 2014.

Rodriguez, R. D., Sheremet, E., Deckert-Gaudig, T., Chaneac, C., Hietschold, M., Deckert, V., and Zahn, D. R. T.: Surface- and tip-enhanced Raman spectroscopy reveals spinwaves in iron oxide nanoparticles, Nanoscale, 7, 9545-9551, https://doi.org/10.1039/C5NR01277E, 2015.

Rosati, B., Paul, A., Iversen, E. M., Massling, A., and Bilde, M.: Reconciling atmospheric water uptake by hydrate forming salts, Environ. Sci.-Proc. Imp., 22, 1759-1767, 2020.
Rovelli, G., Miles, R. E. H., Reid, J. P., and Clegg, S. L.: Accurate Measurements of Aerosol Hygroscopic Growth over a Wide Range in Relative Humidity, J. Phys. Chem. A, 120, 4376-4388, https://doi.org/10.1021/acs.jpca.6b04194, 2016.

Roy, P., Mael, L. E., Makhnenko, I., Martz, R., Grassian, V. H., and Dutcher, C. S.: Temperature-Dependent Phase Transitions of Aqueous Aerosol Droplet Systems in Microfluidic Traps, ACS Earth and Space Chemistry, 4, 1527-1539, https://doi.org/10.1021/acsearthspacechem.0c00114, 2020.

Rygula, A., Majzner, K., Marzec, K. M., Kaczor, A., Pilarczyk, M., and Baranska, M.: Raman spectroscopy of proteins: a review, J. Raman Spectrosc., 44, 1061-1076, 2013.

Sahoo, S. K., Umapathy, S., and Parker, A. W.: Time-Resolved Resonance Raman Spectroscopy: Exploring Reactive Intermediates, Appl. Spectrosc., 65, 1087-1115, 2011.

Saniel, M. B. B., Lim, L. H. V., and Lamorena, R. B.: An Initial Study on the Feasibility of Using Rudimentary SERS in Quick Chemical Assessment of Ambient Aerosols, ChemistrySelect, 4, 14082-14090, https://doi.org/10.1002/slct.201903479, 2019.

Sauerwein, M. and Chan, C. K.: Heterogeneous uptake of ammonia and dimethylamine into sulfuric and oxalic acid particles, Atmos. Chem. Phys., 17, 6323-6339, https://doi.org/10.5194/acp17-6323-2017, 2017.

Scharko, N. K., Berke, A. E., and Raff, J. D.: Release of Nitrous Acid and Nitrogen Dioxide from Nitrate Photolysis in Acidic Aqueous Solutions, Environ. Sci. Technol., 48, 11991-12001, https://doi.org/10.1021/es503088x, 2014.

Schill, G. P., De Haan, D. O., and Tolbert, M. A.: Heterogeneous Ice Nucleation on Simulated Secondary Organic Aerosol, Environ. Sci. Technol., 48, 1675-1682, https://doi.org/10.1021/es4046428, 2014.

Scolaro, S., Sobanska, S., Barbillat, J., Laureyns, J., Louis, F., Petitprez, D., and Brémard, C.: Confocal Raman imaging and atomic force microscopy of the surface reaction of $\mathrm{NO}_{2}$ and $\mathrm{NaCl}(100)$ under humidity, J. Raman Spectrosc., 40, 157-163, 2009.

Seinfeld, J. H. and Pandis, S. N.: Atmospheric chemistry and physics: from air pollution to climate change, 3rd edn., John Wiley and Sons, ISBN 978-1-118-94740-1, 2016.

Seng, S., Guo, F., Tobon, Y. A., Ishikawa, T., Moreau, M., Ishizaka, S., and Sobanska, S.: Deliquescence behavior of photoirradiated single $\mathrm{NaNO}_{3}$ droplets, Atmos. Environ., 183, 33-39, https://doi.org/10.1016/j.atmosenv.2018.04.007, 2018.

Sengupta, A., Laucks, M. L., Dildine, N., Drapala, E., and Davis, E. J.: Bioaerosol characterization by surface-enhanced Raman spectroscopy (SERS), J. Aerosol Sci., 36, 651-664, https://doi.org/10.1016/j.jaerosci.2004.11.001, 2005.

Setschenow, J.: Über die Konstitution der Salzlösungen auf Grund ihres Verhaltens zu Kohlensäure, Z. Phys. Chem., 4U, 117, https://doi.org/10.1515/zpch-1889-0409, 1889.

Singh, M., Mayya, Y. S., Gaware, J., and Thaokar, R. M.: Levitation dynamics of a collection of charged droplets in an electrodynamic balance, J. Appl. Phys., 121, 054503, https://doi.org/10.1063/1.4974470, 2017.

Singh, M., Thaokar, R., Khan, A., and Mayya, Y. S.: Theoretical analysis of formation of many-drop arrays in a quadrupole electrodynamic balance, Phys. Rev. E, 98, 032202, https://doi.org/10.1103/PhysRevE.98.032202, 2018.

Sivaprakasam, V. and Hart, M. B.: Surface-Enhanced Raman Spectroscopy for Environmental Monitor- 
ing of Aerosols, ACS Omega, 6, 10150-10159 https://doi.org/10.1021/acsomega.1c00207, 2021.

Sivaprakasam, V., Hart, M. B., and Eversole, J. D.: Surface Enhanced Raman Spectroscopy of Individual Suspended Aerosol Particles, J. Phys. Chem. C, 121, 22326-22334, https://doi.org/10.1021/acs.jpcc.7b05310, 2017.

Smith, J. D., Kroll, J. H., Cappa, C. D., Che, D. L., Liu, C. L., Ahmed, M., Leone, S. R., Worsnop, D. R., and Wilson, K. R.: The heterogeneous reaction of hydroxyl radicals with submicron squalane particles: a model system for understanding the oxidative aging of ambient aerosols, Atmos. Chem. Phys., 9, 3209-3222, https://doi.org/10.5194/acp-9-3209-2009, 2009.

Sobanska, S., Falgayrac, G., Laureyns, J., and Brémard, C.: Chemistry at level of individual aerosol particle using multivariate curve resolution of confocal Raman image, Spectrochim. Acta A, 64, 1102-1109, https://doi.org/10.1016/j.saa.2005.11.038, 2006.

Sobanska, S., Falgayrac, G., Rimetz-Planchon, J., Perdrix, E., Brémard, C., and Barbillat, J.: Resolving the internal structure of individual atmospheric aerosol particle by the combination of Atomic Force Microscopy, ESEM-EDX, Raman and ToF-SIMS imaging, Microchem. J., 114, 89-98, https://doi.org/10.1016/j.microc.2013.12.007, 2014.

Socrates, G.: Infrared and Raman characteristic group frequencies: tables and charts, John Wiley and Sons, ISBN 978-0-470-093078, 2004.

Song, M., Marcolli, C., Krieger, U., Zuend, A., and Peter, T.: Liquid-liquid phase separation in aerosol particles: Dependence on $\mathrm{O}: \mathrm{C}$, organic functionalities, and compositional complexity, Geophys. Res. Lett., 39, L19801, https://doi.org/10.1029/2012GL052807, 2012a.

Song, M., Marcolli, C., Krieger, U. K., Zuend, A., and Peter, T.: Liquid-liquid phase separation and morphology of internally mixed dicarboxylic acids/ammonium sulfate/water particles, Atmos. Chem. Phys., 12, 2691-2712, https://doi.org/10.5194/acp12-2691-2012, 2012b.

Song, M., Marcolli, C., Krieger, U. K., Lienhard, D. M., and Peter, T.: Morphologies of mixed organic/inorganic/aqueous aerosol droplets, Faraday Discuss., 165, 289-316, 2013.

Song, M., Ham, S., Andrews, R. J., You, Y., and Bertram, A. K.: Liquid-liquid phase separation in organic particles containing one and two organic species: importance of the average O:C, Atmos. Chem. Phys., 18, 12075-12084, https://doi.org/10.5194/acp-18-12075-2018, 2018.

Steer, B., Gorbunov, B., Price, M. C., and Podoleanu, A.: Raman spectroscopic identification of size-selected airborne particles for quantitative exposure assessment, Meas. Sci. Technol.,, 27, 045801, https://doi.org/10.1088/0957-0233/27/4/045801, 2016.

Stewart, D. J., Cai, C., Nayler, J., Preston, T. C., Reid, J. P., Krieger, U. K., Marcolli, C., and Zhang, Y. H.: Liquid-Liquid Phase Separation in Mixed Organic/Inorganic Single Aqueous Aerosol Droplets, J. Phys. Chem. A, 119, 4177-4190, https://doi.org/10.1021/acs.jpca.5b01658, 2015.

Su, H., Cheng, Y., and Pöschl, U.: New Multiphase Chemical Processes Influencing Atmospheric Aerosols, Air Quality, and Climate in the Anthropocene, Accounts Chem. Res., 53, 2034 2043, https://doi.org/10.1021/acs.accounts.0c00246, 2020.

Sullivan, R. C., Boyer-Chelmo, H., Gorkowski, K., and Beydoun, H.: Aerosol Optical Tweezers Elucidate the Chemistry, Acidity, Phase Separations, and Morphology of Atmo- spheric Microdroplets, Accounts Chem. Res., 53, 2498-2509, https://doi.org/10.1021/acs.accounts.0c00407, 2020.

Sun, Z., Duan, F., He, K., Du, J., Yang, L., Li, H., Ma, T., and Yang, S.: Physicochemical analysis of individual atmospheric fine particles based on effective surfaceenhanced Raman spectroscopy, J. Environ. Sci., 75, 388-395, https://doi.org/10.1016/j.jes.2018.06.006, 2019a.

Sun, Z., Duan, F., He, K., Du, J., and Zhu, L.: Sulfate-nitrateammonium as double salts in $\mathrm{PM}_{2.5}$ : Direct observations and implications for haze events, Sci. Total Environ., 647, 204-209, https://doi.org/10.1016/j.scitotenv.2018.07.107, 2019b.

Tahir, M. A., Zhang, X., Cheng, H., Xu, D., Feng, Y., Sui, G., Fu, H., Valev, V. K., Zhang, L., and Chen, J.: Klarite as a label-free SERS-based assay: a promising approach for atmospheric bioaerosol detection, Analyst, 145, 277-285, https://doi.org/10.1039/C9AN01715A, 2020.

Talari, A. C. S., Movasaghi, Z., Rehman, S., and Rehman, I. U.: Raman spectroscopy of biological tissues, Appl. Spectrosc. Rev., 50, 46-111, 2015.

Tan, Y., Perri, M. J., Seitzinger, S. P., and Turpin, B. J.: Effects of precursor concentration and acidic sulfate in aqueous glyoxal$\mathrm{OH}$ radical oxidation and implications for secondary organic aerosol, Environ. Sci. Technol., 43, 8105-8112, 2009.

Tang, M. J., Camp, J. C. J., Rkiouak, L., McGregor, J., Watson, I. M., Cox, R. A., Kalberer, M., Ward, A. D., and Pope, F. D.: Heterogeneous Interaction of $\mathrm{SiO}_{2}$ with $\mathrm{N}_{2} \mathrm{O}_{5}$ : Aerosol Flow Tube and Single Particle Optical LevitationRaman Spectroscopy Studies, J. Phys. Chem. A, 118, 88178827, https://doi.org/10.1021/jp506753c, 2014.

Tang, M., Chan, C. K., Li, Y. J., Su, H., Ma, Q., Wu, Z., Zhang, G., Wang, Z., Ge, M., Hu, M., He, H., and Wang, X.: A review of experimental techniques for aerosol hygroscopicity studies, Atmos. Chem. Phys., 19, 12631-12686, https://doi.org/10.5194/acp-1912631-2019, 2019.

Tian, X., Chu, Y., and Chan, C. K.: Reactive Uptake of Monoethanolamine by Sulfuric Acid Particles and Hygroscopicity of Monoethanolaminium Salts, Environ. Sci. Tech. Let., 9, 1621, https://doi.org/10.1021/acs.estlett.1c00880, 2022.

Tirella, P. N., Craig, R. L., Tubbs, D. B., Olson, N. E., Lei, Z., and Ault, A. P.: Extending surface enhanced Raman spectroscopy (SERS) of atmospheric aerosol particles to the accumulation mode (150-800 nm), Environ. Sci.-Proc. Imp., 20, 1570-1580, https://doi.org/10.1039/C8EM00276B, 2018.

Tobon, Y. A., Seng, S., Picone, L. A., Bava, Y. B., Juncal, L. C., Moreau, M., Romano, R. M., Barbillat, J., and Sobanska, S.: Photochemistry of single particles using acoustic levitation coupled with Raman microspectrometry, J. Raman Spectrosc., 48, 11351137, https://doi.org/10.1002/jrs.5181, 2017.

Tobon, Y. A., El Hajj, D., Seng, S., Bengrad, F., Moreau, M., Visez, N., Chiapello, I., Crumeyrolle, S., and Choël, M.: Impact of the particle mixing state on the hygroscopicity of internally mixed sodium chloride-ammonium sulfate single droplets: a theoretical and experimental study, Phys. Chem. Chem. Phys., 23, 1439114403, 2021.

Tolles, W. M., Nibler, J., McDonald, J., and Harvey, A.: A review of the theory and application of coherent anti-Stokes Raman spectroscopy (CARS), Appl. Spectrosc., 31, 253-271, 1977.

Treuel, L., Pederzani, S., and Zellner, R.: Deliquescence behaviour and crystallisation of ternary ammonium sulfate/dicarboxylic 
acid/water aerosols, Phys. Chem. Chem. Phys., 11, 7976-7984, https://doi.org/10.1039/B905007H, 2009.

Tripathi, A., Jabbour, R. E., Guicheteau, J. A., Christesen, S. D., Emge, D. K., Fountain, A. W., Bottiger, J. R., Emmons, E. D., and Snyder, A. P.: Bioaerosol Analysis with Raman Chemical Imaging Microspectroscopy, Anal. Chem., 81, 6981-6990, https://doi.org/10.1021/ac901074c, 2009.

Tsai, J.-H. M., Harrison, J. G., Martin, J. C., Hamilton, T. P., van der Woerd, M., Jablonsky, M. J., and Beckman, J. S.: Role of Conformation of Peroxynitrite Anion (ONOO-) with Its Stability and Toxicity, J. Am. Chem. Soc., 116, 4115-4116, https://doi.org/10.1021/ja00088a072, 1994.

Uraoka, M., Maegawa, K., and Ishizaka, S.: Raman Spectroscopy of Single Light-Absorbing Carbonaceous Particles Levitated in Air Using an Annular Laser Beam, Anal. Chem., 89, 12866-12871, https://doi.org/10.1021/acs.analchem.7b03455, 2017.

Vejpongsa, I., Suvachittanont, S., Klinklan, N., Thongyen, T., Veres, M., and Szymanski, W. W.: Deliberation between $\mathrm{PM}_{1}$ and $\mathrm{PM}_{2.5}$ as air quality indicators based on comprehensive characterization of urban aerosols in Bangkok, Thailand, Particuology, 35, 1-9, https://doi.org/10.1016/j.partic.2017.05.001, 2017.

Wang, C., Pan, Y.-L., Hill, S. C., and Redding, B.: Photophoretic trapping-Raman spectroscopy for single pollens and fungal spores trapped in air, J. Quant. Spectrosc. Ra., 153, 4-12, 2015.

Wang, M., Zheng, N., Zhao, D., Shang, J., and Zhu, T.: Using Micro-Raman Spectroscopy to Investigate Chemical Composition, Mixing States, and Heterogeneous Reactions of Individual Atmospheric Particles, Environ. Sci. Technol., 55, 10243-10254, https://doi.org/10.1021/acs.est.1c01242, 2021.

Wang, W., Lei, T., Zuend, A., Su, H., Cheng, Y., Shi, Y., Ge, M., and Liu, M.: Effect of mixing structure on the water uptake of mixtures of ammonium sulfate and phthalic acid particles, Atmos. Chem. Phys., 21, 2179-2190, https://doi.org/10.5194/acp21-2179-2021, 2021.

Wang, X., Jing, B., Tan, F., Ma, J., Zhang, Y., and Ge, M.: Hygroscopic behavior and chemical composition evolution of internally mixed aerosols composed of oxalic acid and ammonium sulfate, Atmos. Chem. Phys., 17, 12797-12812, https://doi.org/10.5194/acp-17-12797-2017, 2017.

Wang, Y., Ma, J.-B., Zhou, Q., Pang, S.-F., and Zhang, Y.-H.: Hygroscopicity of Mixed Glycerol/ $\mathrm{Mg}\left(\mathrm{NO}_{3}\right)_{2}$ /Water Droplets Affected by the Interaction between Magnesium Ions and Glycerol Molecules, J. Phys. Chem. B, 119, 5558-5566, https://doi.org/10.1021/acs.jpcb.5b00458, 2015.

Wei, H., Vejerano, E. P., Leng, W., Huang, Q., Willner, M. R., Marr, L. C., and Vikesland, P. J.: Aerosol microdroplets exhibit a stable pH gradient, P. Natl. Acad. Sci. USA, 115, 7272-7277, https://doi.org/10.1073/pnas.1720488115, 2018.

Wheeler, M. J., Mason, R. H., Steunenberg, K., Wagstaff, M., Chou, C., and Bertram, A. K.: Immersion Freezing of Supermicron Mineral Dust Particles: Freezing Results, Testing Different Schemes for Describing Ice Nucleation, and Ice Nucleation Active Site Densities, J. Phys. Chem. A, 119, 4358-4372, https://doi.org/10.1021/jp507875q, 2015.

Willis, M. D., Rovelli, G., and Wilson, K. R.: Combining Mass Spectrometry of Picoliter Samples with a Multicompartment Electrodynamic Trap for Probing the Chemistry of Droplet Arrays, Anal. Chem., 92, 11943-11952, https://doi.org/10.1021/acs.analchem.0c02343, 2020.
Wise, M. E., Baustian, K. J., and Tolbert, M. A.: Internally mixed sulfate and organic particles as potential ice nuclei in the tropical tropopause region, P. Natl. Acad. Sci. USA, 107, 6693-6698, 2010 .

Wise, M. E., Baustian, K. J., Koop, T., Freedman, M. A., Jensen, E. J., and Tolbert, M. A.: Depositional ice nucleation onto crystalline hydrated $\mathrm{NaCl}$ particles: a new mechanism for ice formation in the troposphere, Atmos. Chem. Phys., 12, 1121-1134, https://doi.org/10.5194/acp-12-1121-2012, 2012.

Wu, F.-M., Wang, X.-W., Jing, B., Zhang, Y.-H., and Ge, M.-F.: Liquid-liquid phase separation in internally mixed magnesium sulfate/glutaric acid particles, Atmos. Environ., 178, 286-292, https://doi.org/10.1016/j.atmosenv.2018.02.012, 2018.

Wu, H. B. and Chan, C. K.: Effects of potassium nitrate on the solid phase transitions of ammonium nitrate particles, Atmos. Environ., 42, 313-322, 2008.

Wu, H. B., Chan, M. N., and Chan, C. K.: FTIR Characterization of Polymorphic Transformation of Ammonium Nitrate, Aerosol Sci. Tech., 41, 581-588, https://doi.org/10.1080/02786820701272038, 2007.

Wu, L., Becote, C., Sobanska, S., Flaud, P.-M., Perraudin, E., Villenave, E., Song, Y.-C., and Ro, C.-U.: Hygroscopic behavior of aerosols generated from solutions of 3-methyl1,2,3-butanetricarboxylic acid, its sodium salts, and its mixtures with $\mathrm{NaCl}$, Atmos. Chem. Phys., 20, 14103-14122, https://doi.org/10.5194/acp-20-14103-2020, 2020.

Wu, Z., Wang, Y., Tan, T., Zhu, Y., Li, M., Shang, D., Wang, H., Lu, K., Guo, S., Zeng, L., and Zhang, Y.: Aerosol Liquid Water Driven by Anthropogenic Inorganic Salts: Implying Its Key Role in Haze Formation over the North China Plain, Environ. Sci. Tech. Let., 5, 160-166, https://doi.org/10.1021/acs.estlett.8b00021, 2018.

Xu, G., Cheng, H., Jones, R., Feng, Y., Gong, K., Li, K., Fang, X., Tahir, M. A., Valev, V. K., and Zhang, L.: Surface-Enhanced Raman Spectroscopy Facilitates the Detection of Microplastics $<1 \mu \mathrm{m}$ in the Environment, Environ. Sci. Technol., 54, 1559415603, https://doi.org/10.1021/acs.est.0c02317, 2020.

Xu, R., Ge, Y., Kwong, K. C., Poon, H. Y., Wilson, K. R., Yu, J. Z., and Chan, M. N.: Inorganic Sulfur Species Formed upon Heterogeneous $\mathrm{OH}$ Oxidation of Organosulfates: A Case Study of Methyl Sulfate, ACS Earth and Space Chemistry, 4, 2041-2049, https://doi.org/10.1021/acsearthspacechem.0c00209, 2020.

Ye, J., Abbatt, J. P. D., and Chan, A. W. H.: Novel pathway of $\mathrm{SO}_{2}$ oxidation in the atmosphere: reactions with monoterpene ozonolysis intermediates and secondary organic aerosol, Atmos. Chem. Phys., 18, 5549-5565, https://doi.org/10.5194/acp18-5549-2018, 2018.

Yeung, M. C. and Chan, C. K.: Water Content and Phase Transitions in Particles of Inorganic and Organic Species and their Mixtures Using Micro-Raman Spectroscopy, Aerosol Sci. Tech., 44, 269280, https://doi.org/10.1080/02786820903583786, 2010.

Yeung, M. C., Ling, T. Y., and Chan, C. K.: Effects of the Polymorphic Transformation of Glutaric Acid Particles on Their Deliquescence and Hygroscopic Properties, J. Phys. Chem. A, 114, 898-903, https://doi.org/10.1021/jp908250v, 2010.

You, Y., Renbaum-Wolff, L., Carreras-Sospedra, M., Hanna, S. J., Hiranuma, N., Kamal, S., Smith, M. L., Zhang, X., Weber, R. J., Shilling, J. E., Dabdub, D., Martin, S. T., and Bertram, A. $\mathrm{K}$.: Images reveal that atmospheric particles can undergo liquid- 
liquid phase separations, P. Natl. Acad. Sci. USA, 109, 13188, https://doi.org/10.1073/pnas.1206414109, 2012.

Yu, J.-Y., Zhang, Y., Tan, S.-H., Liu, Y., and Zhang, Y.-H.: Observation on the Ion Association Equilibria in $\mathrm{NaNO}_{3}$ Droplets Using Micro-Raman Spectroscopy, J. Phys. Chem. B, 116, 1258112589, https://doi.org/10.1021/jp306367v, 2012.

Yu, T., Zhao, D., Song, X., and Zhu, T.: $\mathrm{NO}_{2}$-initiated multiphase oxidation of $\mathrm{SO}_{2}$ by $\mathrm{O}_{2}$ on $\mathrm{CaCO}_{3}$ particles, Atmos. Chem. Phys., 18, 6679-6689, https://doi.org/10.5194/acp-186679-2018, 2018.

Zangmeister, C. D. and Pemberton, J. E.: Raman Spectroscopy of the Reaction of Sodium Chloride with Nitric Acid: Sodium Nitrate Growth and Effect of Water Exposure, J. Phys. Chem. A, 105, 3788-3795, https://doi.org/10.1021/jp003374n, 2001.

Zardini, A. A., Sjogren, S., Marcolli, C., Krieger, U. K., Gysel, M., Weingartner, E., Baltensperger, U., and Peter, T.: A combined particle trap/HTDMA hygroscopicity study of mixed inorganic/organic aerosol particles, Atmos. Chem. Phys., 8, 55895601, https://doi.org/10.5194/acp-8-5589-2008, 2008.

Zhang, C., Ma, N., Fan, F., Yang, Y., Größ, J., Yan, J., Bu, L., Wang, Y., and Wiedensohler, A.: Hygroscopic growth of aerosol particles consisted of oxalic acid and its internal mixture with ammonium sulfate for the relative humidity ranging from $80 \%$ to $99.5 \%$, Atmos. Environ., 252, 118318, https://doi.org/10.1016/j.atmosenv.2021.118318, 2021.

Zhang, F., Yu, X., Sui, X., Chen, J., Zhu, Z., and Yu, X.-Y.: Evolution of aqSOA from the Air-Liquid Interfacial Photochemistry of Glyoxal and Hydroxyl Radicals, Environ. Sci. Technol., 53, 10236--10245, 2019.

Zhang, R., Wang, G., Guo, S., Zamora, M. L., Ying, Q., Lin, Y., Wang, W., Hu, M., and Wang, Y.: Formation of urban fine particulate matter, Chem. Rev., 115, 3803-3855, 2015.

Zhang, R., Gen, M., Huang, D., Li, Y., and Chan, C. K.: Enhanced Sulfate Production by Nitrate Photolysis in the Presence of Halide Ions in Atmospheric Particles, Environ. Sci. Technol., 54, 3831-3839, https://doi.org/10.1021/acs.est.9b06445, 2020.

Zhang, R., Gen, M., Fu, T.-M., and Chan, C. K.: Production of Formate via Oxidation of Glyoxal Promoted by Particulate Nitrate Photolysis, Environ. Sci. Technol., 55, 5711-5720, https://doi.org/10.1021/acs.est.0c08199, 2021.

Zhang, R., Gen, M., Liang, Z., Li, Y. J., and Chan, C. K.: Photochemical Reactions of Glyoxal during Particulate Ammonium Nitrate Photolysis: Brown Carbon Formation, Enhanced Glyoxal Decay, and Organic Phase Formation, Environ. Sci. Technol., 56, 1605-1614, https://doi.org/10.1021/acs.est.1c07211, 2022.

Zhang, Y., Bao, F., Li, M., Xia, H., Huang, D., Chen, C., and Zhao, J.: Photoinduced Uptake and Oxidation of $\mathrm{SO}_{2}$ on Beijing Urban $\mathrm{PM}_{2.5}$, Environ. Sci. Technol., 54, 14868-14876, https://doi.org/10.1021/acs.est.0c01532, 2020.

Zhang, Y.-H. and Chan, C. K.: Study of Contact Ion Pairs of Supersaturated Magnesium Sulfate Solutions Using Raman Scattering of Levitated Single Droplets, J. Phys. Chem. A, 104, 9191-9196, https://doi.org/10.1021/jp0013659, 2000.
Zhang, Y.-H. and Chan, C. K.: Observations of Water Monomers in Supersaturated $\mathrm{NaClO}_{4}, \mathrm{LiClO}_{4}$, and $\mathrm{Mg}\left(\mathrm{ClO}_{4}\right)_{2}$ Droplets Using Raman Spectroscopy, J. Phys. Chem. A, 107, 5956-5962, https://doi.org/10.1021/jp0271256, 2003.

Zhang, Y.-H., Choi, M. Y., and Chan, C. K.: Relating Hygroscopic Properties of Magnesium Nitrate to the Formation of Contact Ion Pairs, J. Phys. Chem. A, 108, 1712-1718, https://doi.org/10.1021/jp036524d, 2004.

Zhao, D., Song, X., Zhu, T., Zhang, Z., Liu, Y., and Shang, J.: Multiphase oxidation of $\mathrm{SO}_{2}$ by $\mathrm{NO}_{2}$ on $\mathrm{CaCO}_{3}$ particles, Atmos. Chem. Phys., 18, 2481-2493, https://doi.org/10.5194/acp18-2481-2018, 2018.

Zheng, G., Su, H., Wang, S., Andreae, M. O., Pöschl, U., and Cheng, Y.: Multiphase buffer theory explains contrasts in atmospheric aerosol acidity, Science, 369, 1374-1377, 2020.

Zheng, H., Song, S., Sarwar, G., Gen, M., Wang, S., Ding, D., Chang, X., Zhang, S., Xing, J., and Sun, Y.: Contribution of Particulate Nitrate Photolysis to Heterogeneous Sulfate Formation for Winter Haze in China, Environ. Sci. Tech. Let., 7, 632-638, 2020.

Zheng, L., Kulkarni, P., Birch, M. E., Ashley, K., and Wei, S.: Analysis of Crystalline Silica Aerosol Using Portable Raman Spectrometry: Feasibility of Near Real-Time Measurement, Anal. Chem., 90, 6229-6239, https://doi.org/10.1021/acs.analchem.8b00830, 2018.

Zhou, H., Yang, D., Ivleva, N. P., Mircescu, N. E., Niessner, R., and Haisch, C.: SERS Detection of Bacteria in Water by in Situ Coating with Ag Nanoparticles, Anal. Chem., 86, 1525-1533, https://doi.org/10.1021/ac402935p, 2014.

Zhou, H., Yang, D., Ivleva, N. P., Mircescu, N. E., Schubert, S., Niessner, R., Wieser, A., and Haisch, C.: Label-Free in Situ Discrimination of Live and Dead Bacteria by SurfaceEnhanced Raman Scattering, Anal. Chem., 87, 6553-6561, https://doi.org/10.1021/acs.analchem.5b01271, 2015.

Zhou, Q., Pang, S.-F., Wang, Y., Ma, J.-B., and Zhang, Y.-H.: Confocal Raman studies of the evolution of the physical state of mixed phthalic acid/ammonium sulfate aerosol droplets and the effect of substrates, J. Phys. Chem. B, 118, 6198-6205, 2014.

Zhu, F., Zhou, H., Wang, X., Zhou, Y., Liu, H., Fang, C., and Fang, Y.: Raman spectroscopy and ab initio quantum chemical calculations of ion association behavior in calcium nitrate solution, J. Raman Spectrosc., 49, 852-861, https://doi.org/10.1002/jrs.5349, 2018.

Zobrist, B., Soonsin, V., Luo, B. P., Krieger, U. K., Marcolli, C., Peter, T., and Koop, T.: Ultra-slow water diffusion in aqueous sucrose glasses, Phys. Chem. Chem. Phys., 13, 3514-3526, 2011. 